NBER WORKING PAPER SERIES

\title{
HIERARCHIES, SPECIALIZATION, AND THE UTILIZATION OF KNOWLEDGE: THEORY AND EVIDENCE FROM THE LEGAL SERVICES INDUSTRY
}

\author{
Luis Garicano \\ Thomas N. Hubbard \\ Working Paper 10432 \\ http://www.nber.org/papers/w10432
NATIONAL BUREAU OF ECONOMIC RESEARCH 1050 Massachusetts Avenue
Cambridge, MA 02138
April 2004

We thank Jim Brickley, Bob Gibbons, Lynn Riggs, Paul Oyer, Pedro Vicente, and seminar participants at Brown, Carnegie-Mellon, Chicago, Columbia, Harvard, Indiana, MIT, Rochester, Toronto, UCLA, UCSD, Wharton, and Yale, and at the American Economic Association meetings for useful comments. The research in the paper was conducted while the authors were Census Bureau research associates at the Chicago Research Data Center. Research results and conclusions are those of the authors and do not necessarily indicate concurrence by the Bureau of the Census. This paper has been screened to insure that no confidential data are revealed. The views expressed herein are those of the author(s) and not necessarily those of the National Bureau of Economic Research.

(C2004 by Luis Garicano and Thomas N. Hubbard. All rights reserved. Short sections of text, not to exceed two paragraphs, may be quoted without explicit permission provided that full credit, including $\odot$ notice, is given to the source. 
Hierarchies, Specialization, and the Utilization of Knowledge:

Theory and Evidence from the Legal Services Industry

Luis Garicano and Thomas N. Hubbard

NBER Working Paper No. 10432

April 2004

JEL No. D23, K40, L14, L22, L84

\title{
$\underline{\text { ABSTRACT }}$
}

What role do hierarchies play with respect to the organization of production and what determines their structure? We develop an equilibrium model of hierarchical organization, then provide empirical evidence using confidential data on thousands of law offices from the 1992 Census of Services. The driving force in the model is increasing returns in the utilization of acquired knowledge. We show how the equilibrium assignment of individuals to hierarchical positions varies with the degree to which their human capital is field-specialized, then show how this equilibrium changes with the extent of the market. We find empirical evidence consistent with a central proposition of the model: the share of lawyers that work in hierarchies and the ratio of associates to partners increases as market size increases and lawyers field-specialize. Other results provide evidence against alternative interpretations that emphasize unobserved differences in the distribution of demand or "firm size effects," and lend additional support to the view that a role hierarchies play in legal services is to help exploit increasing returns associated with the utilization of human capital.

\author{
Luis Garicano \\ University of Chicago \\ Graduate School of Business \\ 1101 East 58th Street \\ Chicago, IL 60637 \\ luis.garicano@gsb.uchicago.edu \\ Thomas N. Hubbard \\ University of Chicago \\ Graduate School of Business \\ 1101 East 58th Street \\ Chicago, IL 60637 \\ and NBER \\ thomas.hubbard@gsb.uchicago.edu
}




\section{Introduction}

What role do hierarchies play with respect to the organization of production? What factors determine their structure? An extensive literature has considered these questions over the last 40 years, emphasizing the role hierarchies can play with respect to information processing and monitoring. This literature has, in our view, two shortcomings. First, it is almost entirely theoretical. Despite the fact that hierarchies are a pervasive means of organizing individuals, there has been little or no systematic empirical work on these issues in the economics literature. Second, in focusing on information processing and monitoring, most theories in this literature have set aside the role hierarchies can play with respect to exploiting increasing returns associated with the utilization of human capital. ${ }^{1}$

This paper examines theoretically and empirically hierarchies' role in the organization of knowledge-intensive production. ${ }^{2}$ Our empirical work focuses on the legal services industry. We start by providing some stylized facts about hierarchies in legal services and discuss how they cannot be accommodated within several existing views of hierarchies. For example, views that emphasize upper-level individuals' role in monitoring or coordinating teams of lower-level individuals cannot accommodate the fact that single-associate offices are not unusual.

We then develop an equilibrium model of hierarchies that can capture these stylized facts and generates additional propositions. The driving force in this model is increasing returns associated with the utilization of knowledge: an individual who acquires a piece of knowledge incurs a fixed cost, independent of the knowledge's subsequent utilization. Efficient knowledge utilization requires that this piece of knowledge be utilized as much as possible. ${ }^{3}$ We show that this force generates clear relationships between individuals' horizontal specialization -- the degree to which individuals field-specialize -- and hierarchical organization and natural connections between these variables and market size. The logic of this model follows.

\footnotetext{
${ }^{1}$ We discuss the theoretical literature in Section 2.3. Perhaps the only recent systematic empirical work is Rajan and Wulf (2003), which analyzes hierarchies of top-level managers in very large firms. This work shows that such hierarchies have "flattened" over time.

${ }^{2}$ Following the existing literature (see e.g., Radner (1992) for a review), we use the term "hierarchy" to simply mean a rank-ordering of individuals in which multiple individuals may have the same rank. This ordering may, but need not, carry implications with respect to authority or control rights.

${ }^{3}$ Rosen $(1983,2002)$ repeatedly calls attention to the importance of this source of increasing returns. From his 2002 presidential address to the AEA: "for the economy as a whole, the most important reason by far for specialization and division of labor are scale economies in utilizing acquired skills." (2002:10)
} 
Consider first the determinants of horizontal specialization. ${ }^{4}$ Given economies of scale in the utilization of knowledge, individuals prefer to acquire a narrow base of knowledge and utilize it as intensively as possible, dealing only with problems of a particular type. However, the arrival of problems of a given type is uncertain, and individuals diversify in order to increase the utilization of their time. In equilibrium, generalists and specialists co-exist - generalists arbitrage unpredictable differences in demand between fields and receive more stable earnings, while specialists use knowledge more intensively and earn more when the demand for their field is high.

Consider now the role of hierarchies. ${ }^{5}$ Suppose that individuals not only choose the field or fields in which they acquire knowledge, but also choose the depth of their knowledge within fields - they can learn to solve only the easier problems in a field, or they can learn also to solve the more difficult ones. For individuals to find it worthwhile to learn solutions to difficult problems, they must be shielded from the easier ones; otherwise their utilization of expert knowledge is too low to support its acquisition. Hierarchies enable individuals to increase the utilization of expert knowledge by shielding experts from simple problems and allowing them to specialize in problems they have a comparative advantage in addressing.

The focus of our theoretical analysis is on the interaction between these two elements, horizontal specialization and hierarchy. In equilibrium, the allocation of individuals to fields, the patterns of horizontal specialization, and the hierarchical organization of these individuals result from trade-offs regarding the optimal acquisition and utilization of costly knowledge. We show how this equilibrium is affected, in particular, by the extent of the market. ${ }^{6}$ As the size of the economy increases, aggregate uncertainty about the allocation of demand across fields declines, reducing the value of the arbitrage between fields performed by generalists and increasing equilibrium field specialization. Individuals become "narrower, but deeper," and the benefit of leveraging their expertise increases. As we show, it follows that both the share of individuals who work in hierarchies and the ratio of lower-level to upper-level individuals should increase with market size.

\footnotetext{
4 This aspect of the model draws from Kevin M. Murphy's (1986) unpublished dissertation.

${ }^{5}$ This aspect of the model draws from Garicano (2000).

${ }^{6}$ Although the existence of a relation between division of labor and market size has been discussed since Adam Smith, no previous theoretical work has clarified the relationship between horizontal specialization, hierarchies and the extent of the market.
} 
We test this and other related propositions using a unique data set: confidential data on thousands of law offices from the 1992 Census of Services. These data are a large sample taken from all law offices located in the United States at the time, and contain office-level information on both the hierarchical organization of lawyers (i.e., how many lawyers are partners versus associates) and the field-specialization of lawyers. These data permit us to analyze how law offices' hierarchical organization changes as market size increases and lawyers' human capital changes.

Our empirical evidence is consistent with these propositions. The share of lawyers that work in hierarchies (i.e., at an office with at least one associate) is greater in larger local markets. Other results indicate that this increase is correlated with increases in lawyers' field specialization in a way that is consistent with our model. We de-compose the increase in the share of lawyers who work in hierarchies between increases in the share who are partners and associates; we find that a constant share of lawyers works as partners in hierarchies, but the average number of associates who work under these partners increases. We supplement these main facts with additional analysis. We find that they hold when looking only across small, isolated markets, persist when holding firm size constant, and appear only when analyzing lawyers that primarily serve business rather than individual clients. We also show that these patterns are far weaker when examining the hierarchical margin between lawyers and nonlawyers, a margin where the division of labor between individuals is constrained by regulation. This additional analysis provides evidence against alternative interpretations of our main results that emphasize unobserved differences in the distribution of demand or "firm size effects." Furthermore, it provides additional evidence that is consistent with the view that hierarchies' role within law offices is, in part, to support vertical specialization: our results are stronger at hierarchical margins where the division of labor is arbitrary than constrained, and strongest in segments where vertical specialization is most valuable.

We view these empirical results as important on several dimensions. First, while economists recognize that a large share of economic activity takes place within hierarchies, practically no empirical facts concerning even the first order objects of the theory, such as hierarchies' shape, have followed the extensive theoretical work undertaken in recent years, beyond casual empiricism. Second, understanding the organization of knowledge-intensive production is important, and becoming more so as the share of individuals in advanced 
economies who are "knowledge workers" increases. ${ }^{7}$ We (intentionally) investigate a context where human capital is by far the most important input to production, but believe that our analysis may shed light on the organization of white-collar work more generally. Finally, our analysis, which emphasizes how organizational structures help exploit scale economies associated with individuals' human capital, is a step toward better understanding two issues that are not traditionally associated with the economics of organization: industry structure and wage inequality. We discuss these connections further toward the end of the paper, and intend to explore them more in future research.

More broadly, our theory illuminates an important but understudied driver of economic organization: increasing returns in the utilization of acquired knowledge. Economists since Arrow (1962) and Romer (1986) have recognized that increasing returns from knowledge have important implications for economic growth. Our paper studies the implications of increasing returns from knowledge for economic organization, in particular how hierarchical organization can play an essential role in exploiting these increasing returns. The theory, and our reading of the empirical evidence, suggests that the problem of utilizing knowledge efficiently may influence the organization of knowledge-intensive production more generally.

The paper is organized as follows. Section 2 presents the stylized facts that motivate the model. Section 3 presents the model. Section 4 discusses the data and empirical issues. Section 5 reports our main empirical results. Section 6 concludes.

\section{Hierarchies in Knowledge-Intensive Production: Some Basic Facts About Legal Services Hierarchies and Existing Explanations}

Legal services is an extremely knowledge-intensive industry, which makes it an interesting context to investigate the organization of knowledge-intensive production. Physical assets are unimportant. The main inputs are individuals' time and expertise. These individuals include lawyers and various categories of non-lawyers such as paralegals, legal assistants, and

\footnotetext{
${ }^{7}$ Indeed, recent debates about international outsourcing have been about the organization of knowledge-intensive production such as software-writing. The analysis in this paper informs aspects of these debates that have to do with the division of labor and work flows among knowledge workers; additional research is necessary to analyze its implications when knowledge workers can live in different countries.
} 
secretaries. These human capital inputs are complemented by knowledge bases such as libraries and Lexis-Nexis. The main outputs are legal advice, documents, and representation.

Lawyers differ in the breadth and depth of their knowledge. Many specialize in a single area of the law, such as corporate law, real estate law, negligence law, or probate (estate) law. The fraction of lawyers who field-specialize tends to be greater in larger cities (Garicano and Hubbard (2003)). Lawyers who have the most in-depth knowledge within their field tend also to be field-specialized: for example, experts in tax law are generally specialized in tax law.

Many law offices distinguish between partners and associate lawyers. This distinction reflects lawyers' position within their firm's hierarchy, ${ }^{8}$ and corresponds to two main differences. One is in the division of labor. Associates generally work in teams with at least one partner, and associates tend to handle tasks in which they have a comparative advantage: for example, less knowledge-intensive tasks. The other concerns their contractual position within their firm. Partners are residual claimants on the revenues generated within their firm; associate

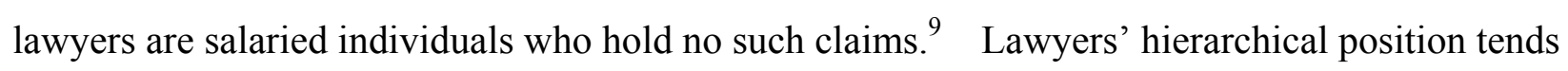
to vary with their experience. While some lawyers start out as partners immediately after passing the bar (these include lawyers who start their own firm, for example), many lawyers start practicing law as associate lawyers, then move on to become partners.

\subsection{Key Stylized Facts}

Table 1 reports some important stylized facts from our main data source, confidential office-level data from the 1992 Census of Services, about the hierarchical organization of lawyers in the United States, focusing on the hierarchical margin between partners and associate lawyers. ${ }^{10}$ These facts motivate our theoretical approach in Section 3.

Panel A reports the distribution of law offices, by the number of associates. $73 \%$ of law offices have no associates: these "non-hierarchies" include, for example, single-lawyer offices and offices where there are several lawyers, all of whom are partners. Another interesting figure

\footnotetext{
${ }^{8}$ There are distinctions within these categories in some firms (e.g., equity partners and non-equity partners). We do not dwell on these other distinctions because our data do not make them.

${ }^{9}$ At firms that are legally organized as partnerships, partners are also liable for claims against any other partner. This is not true for firms operating under other legal forms of organization. Here we focus on differences that hold regardless of the firm's legal form of organization. See below for a further discussion of legal form of organization.

${ }^{10}$ We describe these data in more detail in Section 4, before our main empirical section.
} 
in this row is immediately to the right: $11 \%$ of offices have only one associate. In fact, the modal positive number of associates is one. The second row depicts the distribution of associates across offices. Although most associates work in offices where there are more than five associates, $8 \%$ of associates are the only associates in their office.

The first row of Panel B tabulates the distribution of law offices, by the associate/partner ratio of the office. The striking fact from the first row is that associate/partner ratios tend to be low, even among offices where there is at least one associate. $19 \%$ of offices have associate/partner ratios of one or less (but greater than zero); only $8 \%$ have associate/partner ratios greater than one. Panel C expands upon this by reporting the distribution of "leverage" across lawyers. "Leverage" equals zero for associates, and equals the associate/partner ratio in the office for partners; it is intended to capture the number of lawyers who work under a lawyer. The first two numbers in the first row indicate that about $70 \%$ of lawyers are unleveraged: they are either associates or are partners at offices without associates. The figures in the rest of the row indicate that a key fact from Panel B is not only true when casting things in terms of offices, but in terms of lawyers as well. Even when confining the analysis to offices with associates, a minority of partners work at offices where there are more associates than partners. The other two rows report these figures separately for offices that primarily serve business clients versus individual clients. Although lawyers in offices that serve business clients tend to be more leveraged than those serving individual clients, this key fact is true within both segments.

The second row of Panel B reports the share of lawyers who field-specialize -- that is, who work primarily in one of thirteen fields defined by the Census (e.g., corporate law, tax law) -- by the associate/partner ratio of their office. This share tends to be higher at offices where the associate/partner ratio is greater, increasing from $45 \%$ at offices where this ratio equals zero to over $80 \%$ at offices where it is at least one.

In sum, this table depicts the following stylized facts. First, single-associate offices are not uncommon. Second, associate/partner ratios are low, even when considering only offices with at least one associate and even when restricting the analysis to offices that primarily serve business clients. As we discuss further below, these two facts are difficult to accommodate within some existing views of hierarchies. Third, lawyers' hierarchical organization is correlated with the degree to which lawyers field-specialize. This final fact motivates our theoretical model, which emphasizes how individuals' hierarchical organization varies with their human 
capital, and which produces additional propositions that we investigate in the main empirical sections of the paper.

\subsection{How Do Existing Theories of Hierarchies Fit These Patterns?}

Economic views of hierarchies generally fall under one of two categories: task-related and contractual. The task-related theories are those in which hierarchies correspond to a division of labor whereby upper-level individuals' job is different from that of lower level individuals. In our context, these would emphasize differences in what partners and associates do. In contractual views, hierarchies reflect only differences in individuals' contractual position within their firm; here, partners' and associates' contractual positions. We discuss these views in turn in what follows, and discuss instances where their broad empirical implications are inconsistent with some basic patterns in our data.

Task-related Theories. Depending on the role played by upper management, taskrelated theories fall under four classes: monitoring, coordination, control, and knowledge utilization. The last of these, where hierarchies are devices to increase the utilization of knowledge (Garicano 2000), is the basis for the model in Section 3; we discuss here the other three and some empirical implications.

Monitoring theories derive from Alchian and Demsetz (1972), who posit that hierarchies are a response to incentive problems associated with team production. In this view, lower-level individuals are directly involved in production, and upper-level individuals are specialized monitors. The view was elaborated formally by Calvo and Weillisz (1978, 1979) and Qian (1994). Applied to our context, these theories imply hierarchies in which teams of associates solve clients' problems and partners monitor and reward them according to their contribution.

A second view emphasizes coordination aspects of hierarchies. In this view, lower-level individuals perform different tasks and upper-level individuals specialize in coordinating these tasks. Hart and Moore (2003) consider hierarchies as chains of authority that determine priority in decisions over asset allocation, and derive conditions where optimal hierarchies have generalist coordinators on top. Other work concentrates on the information aspects of coordination, focusing on either information aggregation (Radner (1992, 1993), Radner and Van 
Zandt (1992), Bolton and Dewatripont (1994) and Van Zandt (1999)), or on resource allocation (Crémer (1980) Geanakoplos and Milgrom (1991)). In all of these views the manager as coordinator sits above multiple workers in the hierarchy. In our context, these views would imply that teams of associates work on different aspects of a problem, while a non-specialized partner coordinates the associates' work.

The coordination and monitoring views of hierarchies differ in their details, but share a fundamental element: they revolve around team production among lower-level individuals, and thus require there to be multiple lower-level individuals. ${ }^{11}$ Table 1 indicated that this is not always true in our context: there are many law offices with only one associate. These views cannot accommodate single-associate law offices as a possibility. While it is undoubtedly true that partners monitor and coordinate associates' work, especially when associates work in teams, lawyers are organized hierarchically even when incentive and coordination problems associated with team production cannot be an issue.

An alternative view of hierarchies, traditionally identified with radical political economists, ${ }^{12}$ posits that hierarchies exist to allow employers to retain rents and provide them power over their employees by controlling the flow of work to them (Marglin, 1974). In this view, hierarchies exist to serve the purposes of "bosses" rather than for efficiency reasons. An interpretation of this view in our context would hold that partners exercise power through their control of client contacts. We find extreme versions of this view, in which partners only control clients and associates do the work, implausible for explaining law offices where the ratio between associates and partners is low; associate/partner ratios less than or equal to one would require that the office's lawyers collectively spend as much or more time drumming up clients than they do in production. Table 1 showed that associate/partner ratios tend to be low in law offices: even among offices with at least one associate, partners who work at offices where there are more associates than partners are a minority. We therefore doubt that these extreme versions

\footnotetext{
${ }^{11}$ More precisely, resource allocation, monitoring and coordination theories require more than one subordinate; the information processing view (as, e.g. Bolton and Dewatripont, 1994) requires at least one subordinate, as when the optimal hierarchy is a "conveyor belt."

${ }^{12}$ For an early expression of this view see the much cited paper by Marglin (1974) or Rebitzer's (1993) survey. See also Rajan and Zingales (1998) for a modern property-rights-based theory that puts power, through the control of access to assets, at the center of the role of hierarchy, but which differs form traditional "radical views" in that it takes an efficiency perspective.
} 
explain why lawyers are organized into hierarchies. ${ }^{13}$ On the other hand, the view that partners engage in business generating activities as well as production is entirely reasonable, and the model we develop below can accommodate this. In particular, if in-depth knowledge provides lawyers with a comparative advantage in business generating activities as well as in solving difficult problems, hierarchical organization would allow experts to leverage their knowledge in the same way as we depict below.

Contractual Views. As applied to our context, a second class of theories is agnostic about any task differences between partners and associates, but focuses instead on differences in their contractual position within their firm: for example, partners are more permanent members of their firm than associates and share in the proceeds of their firm. Theories within this class have examined the incentive properties of these or similar organizational features: for example, Carmichael (1988) analyzes academic tenure; the distinction between tenured and untenured professors parallels distinctions between partners and associates to some degree. Garicano and Santos (2004) and Levin and Tadelis (2004) analyze the incentive properties of partnerships as revenue-sharing arrangements. The former argues that such arrangements provide individuals incentives to exchange referrals; the latter argues that they encourage individuals to be selective in who they work with. These theories do not analyze how hierarchical organization should vary with either individuals' horizontal specialization or with market size; to our knowledge, neither do other theories that examine only how individuals' incentives vary with their rank, such as those in the "career concerns" literature.

Because our main empirical analysis concerns comparative statics that purely contractual theories do not contemplate, it will not provide evidence either in favor or against this class of theories. However, the stylized facts above provide evidence with respect to one incentivetheoretic strain of this literature: tournament theory. This literature, initiated by Lazear and Rosen (1981) and further developed by Lazear (1995) and in the context of legal services by Galanter and Palay (1991), views hierarchies in terms of incentive schemes that revolve around lower-level individuals' relative performance. Tournament theory has the same problem in our

\footnotetext{
${ }^{13}$ Even Marglin (1974) was cautious in applying this view to knowledge-intensive contexts, distinguishing between "precapitalist" and "capitalist" hierarchies (1974:63) and focusing his analysis on contexts where production requires no special skills (1974:69).
} 
context as the monitoring and coordination views described above: because it revolves around the use of relative performance measures for motivating lower-level individuals, it cannot possibly accommodate single-associate law offices. Although relative performance incentives may be used to motivate associates at many law offices, law offices are organized as hierarchies even in situations where this cannot be the case. ${ }^{14}$

\section{Knowledge Utilization, Specialization and Hierarchy}

The stylized facts above can be easily reconciled within a theory in which hierarchies' role is to exploit increasing returns in the utilization of knowledge. We develop such a model in what follows. In the model, knowledge acquisition involves a fixed cost, independent of its utilization. Economic organization (horizontal specialization and hierarchies), is about exploiting these increasing returns in the presence of two obstacles: the arrival of problems is random, so that specialization is constrained by the prospect of underutilizing agents' time, and individuals do not know the difficulty of problems they themselves cannot solve. The model generates propositions concerning relationships between horizontal specialization, the existence and structure of hierarchies, and extent of the market that we then take to the data. The model focuses on the equilibrium organization of knowledge and abstracts throughout from both incentive considerations and dynamics. ${ }^{15}$

\subsection{The Model}

We consider an economy with $\mathrm{N}$ ex ante identical suppliers of solutions and $\mathrm{N}$ identical demanders. $\mathrm{N}$ is the size of the economy. ${ }^{16}$

\footnotetext{
${ }^{14}$ Other work has cast doubt on the applicability of tournament theory to even large law firms. Kordana (1995) shows that the fraction of associate cohorts large law firms promote varies dramatically from year to year, which is inconsistent with the proposition that promotions are based only on associates' relative performance. He also questions whether individual associates' performance is difficult for other lawyers to evaluate. See also Sander and Williams (1992).

${ }^{15}$ The model indirectly captures some of these organizational dynamics: if agents obtain knowledge through experience, it would follow that agents at the top of hierarchies would tend to be more experienced than those below. Lower-level workers in this model, like apprentices, handle the simplest problems. However, it does not capture the contractual mechanisms that may underlie these organizational dynamics in the face of dynamic incentive trade-offs.

${ }^{16} \mathrm{We}$ assume $\mathrm{N}$ on both sides of the market for simplicity and symmetry. Our results are unchanged if instead of assuming suppliers are inelastically supplied, we assume an elastic supply of agents with a constant wage w.
} 
Demand. Each of the $\mathrm{N}$ demanders faces a continuum of problems in $[0,1]$. Solutions to these problems are equally valuable to these demanders; we normalize a demander's value of solutions to 1 if the entire set is solved. We assume each demander's set of problems can be in one of two fields: field $A$ or $B$, each with probability $1 / 2 .{ }^{17}$

Supply. We assume that within each field problems can be ordered by their level of difficulty, or the learning cost of solutions, indexed by $q$. Agents must first learn the easy problems before learning the hard ones. The ordering of the problems by difficulty implies a cost of learning all problems in a given interval $[0, q]$ given by a function $C(q)$, such that $C^{\prime}>0$ and $C ">0 .{ }^{18}$ Note that this is the source of increasing returns in the model: the cost of acquiring knowledge about problems is independent of its utilization. We assume that agents cannot determine the difficulty of problems they cannot solve themselves, other than the fact that their solutions lie outside their own expertise. This is the key assumption that makes organizing agents into knowledge-based hierarchies valuable, as we discuss later. Finally, we assume that all problems, whether ultimately solved or unsolved, must be handled by some agent; for example because suppliers have to spend time communicating with demanders regardless. Each of the $\mathrm{N}$ suppliers can handle a unit interval of demanders' problems per unit of time. An agent may work on his own or he may work with others, in which case he can pass unsolved problems to other agents.

Timing. First, the $\mathrm{N}$ suppliers choose the breadth and depth of their knowledge and how production should be organized. With respect to breadth, agents can choose to specialize in field $A$ or $B$ or they can choose to be generalists and deal with problems in both fields. Next, the number of demanders who face problems in each of the fields is realized. Finally, the market for solutions clears and production takes place: suppliers make a take-it-or-leave-it offer and use their time and knowledge to address demanders' problems. The equilibrium prices for solutions to problems in fields $A$ and $B$ must be such that markets clear.

Individual suppliers thus face trade-offs with respect to the breadth and depth of their knowledge. Field-specialized agents incur learning costs associated with only one field's problems, but face the possibility that demand in their field might be low. Generalists, on the

\footnotetext{
${ }^{17}$ Nothing in our results depends on this symmetry; having two equally important fields simplifies notation.

${ }^{18}$ The model can be equivalently written in terms of the frequency of the problems instead of their difficulty (see Garicano 2000), with a probability distribution $F(z)$ given by the inverse of the cost function $C(q)$, so that $q=F(z)$.
} 
other hand, incur learning costs associated with both fields' problems, but demand for their services is certain since they can always work in the field with high demand. The benefit of depth within a field is that the agent can solve a greater fraction of demanders' problems; this benefit is greater when they expect the market price of solutions to be higher. The drawback is that more depth implies greater learning costs.

\subsection{Knowledge Depth and Organization in One Field}

To fix ideas and provide a benchmark, first consider a very simple way of organizing supply: suppose there is only one field and each agent confronts the problems of a single demander and addresses these problems himself. The output of each agent, net of learning costs, is then $y=p q-C(q)$, where $p$ equals the market price of a solved interval of problems of length 1.

Now expand the set of possible organizational arrangements. Allow agents to work with one another, so that if they do not know the solution to a problem themselves, they can pass it on to someone else. In this case, under the above assumptions, the optimal organization of problem solving is in a knowledge-based hierarchy: an organization in which individuals are ranked and where there is a one-to-one correspondence between their rank and the depth of their knowledge (Garicano, 2000). ${ }^{19}$ Such organizations allow individuals to "vertically specialize" along the lines of problems' difficulty. Learning about difficult problems is only worthwhile if an agent confronts them often enough. This requires concentrating in solving such problems and avoiding the easy ones. This can be done through hierarchies: the role of lower layers is to protect the knowledge of those in higher layers, allowing experts to specialize in problems they have a comparative advantage in addressing. To simplify, and in accordance with our empirical application, we focus the exposition on two-layer hierarchies.

\footnotetext{
${ }^{19}$ Garicano (2000) characterizes the optimal organization when (1) production requires two activities: physical production and problem solving, and (2) agents can communicate problems' solutions at a cost. That paper shows that, optimally, some agents specialize in physical production and other agents in problem-solving. Problem solvers can communicate their knowledge to many workers, who then use it to produce the good. Here instead, production requires only one activity - problem solving. Higher level agents do not communicate their knowledge to lower level agents, but instead use it when working on problems themselves. In spite of this conceptual difference, the mathematical structure of the model is similar.
} 
Suppose again that only one field exists. Consider the output of a hierarchy with $n+1$ agents, with $n=0,1,2 \ldots,{ }^{20}$ each of whom initially confronts one demander's problems, and where the most knowledgeable agent (the "manager") has learned to solve all problems in $\left[0, \mathrm{q}_{\mathrm{m}}\right]$ and the less knowledgeable ones (the "workers") have learned to solve problems in $\left[0, \mathrm{q}_{\mathrm{w}}\right]$, with $\mathrm{q}_{\mathrm{w}}<\mathrm{q}_{\mathrm{m}}$. We refer to $\mathrm{n}$ as the manager's "leverage." The expected value of the output of the $\mathrm{n}+1$ agents is:

$$
y=p^{e} q_{m}(n+1)-c\left(q_{m}\right)-c\left(q_{w}\right) n,
$$

where $p^{e}$ is the expected equilibrium price of a solved problem, to be characterized later. Note that if $n=0$, this is equal to the output of one agent derived above. Equation (1) says that the agents confront $n+1$ demanders' problems, of which they can solve a share $\mathrm{q}_{m}$. (i.e., those problems whose solution is known at least by the manager). Costs include the learning costs of the manager $c\left(q_{m}\right)$ and the workers $c\left(q_{w}\right) n$.

This expression is subject to two time constraints. First, the $n$ workers spend no more than $\mathrm{n}$ units of time handling a share $\mathrm{q}_{\mathrm{w}}$ of the $(n+1)$ demanders' problems: $(\mathrm{n}+1) \mathrm{q}_{\mathrm{w}} \leq \mathrm{n}$. Second, managers spend their time handling the rest of the problems, since all problems have to be handled by someone and workers cannot identify which problems managers can and cannot solve: $\left(1-q_{w}\right)(n+1) \leq 1$. Satisfying both of these time constraints requires that both be binding, and the two constraints reduce to the single constraint:

$$
\left(1-q_{w}\right)(n+1)=1
$$

The time constraints thus imply a one-to-one relationship between workers' knowledge and the manager's leverage.

Thus managerial earnings are $R=p^{e} q_{m}(n+1)-c\left(q_{m}\right)-c\left(q_{w}\right) n-w n$, subject to (2). Worker's total compensation equals their net wage $w$ plus a compensation for their learning costs $c\left(q_{w}\right)$. Given that agents are ex ante homogeneous, managerial earnings must equal workers' net wage, i.e. $R=w .{ }^{21}$ Substituting this into the expression for managerial earnings, this implies that managers' problem is to choose their knowledge, agents' knowledge, and their leverage to maximize per capita output, that is:

\footnotetext{
${ }^{20}$ Nothing in what follows depends on the number of team members being a natural number; the same results hold when fractions of workers can be used.

${ }^{21}$ Obviously, managers earn more than workers to compensate their greater knowledge. However, like in the original Mincer (1958) formulation of the human capital theory, homogeneous agents get exactly the extra compensation necessarily to compensate for their higher investment, implying that their ex-ante incomes are the same.
} 


$$
w=\max _{q_{m}, q_{w}, n} p^{e} q_{m}-\frac{c\left(q_{m}\right)}{n+1}-c\left(q_{w}\right) \frac{n}{n+1}
$$

subject to constraint (2). Substituting in the constraint, we can rewrite the objective function as:

$$
w=\max _{q_{m}, q_{w}} p^{e} q_{m}-c\left(q_{m}\right)\left(1-q_{w}\right)-c\left(q_{w}\right) q_{w}
$$

The value of increasing the manager's knowledge is that the production of the entire team is greater. The value of workers' knowledge comes from relaxing constraint (2): more knowledgeable workers allow managers to apply their costly knowledge $q_{m}$ to a larger number of problems. This exploits increasing returns. Relaxing this constraint comes at a cost, however, both because per-worker learning costs are greater and because there are more workers. The following proposition, proven in the Appendix, characterizes the comparative statics.

Proposition 1. The knowledge acquired by managers $\left(q_{m}\right)$ and workers $\left(q_{w}\right)$, and managers' leverage (n), are non-decreasing in the price of solutions $p$.

Intuitively, when the returns to depth increase, managers acquire more knowledge and spread it over a larger number of workers. The latter requires workers' knowledge to increase: the manager's time constraint implies that increases in his leverage be accompanied with increases in workers' knowledge. The comparative statics are not strict: if the problems are insufficiently heterogeneous so that $\mathrm{C}(\mathrm{q})$ is not sufficiently convex, it is optimal for managers to learn the solution to the entire range of problems $\left(q_{m}=1\right)$. In that case, increases in $p$ do not lead managers to acquire more in-depth knowledge (they are at a corner), and therefore neither managers' leverage nor workers' knowledge should change.

\subsection{Equilibrium Specialization and Hierarchy with Multiple Fields}

Up to here, we have studied hierarchical organization when there is only one field. Now consider the allocation of agents to fields and hierarchical positions when there are two fields, and each demander's set of problems is either in field A or in field B with equal probability. Let $N_{i}$ be the number of agents who choose to specialize in field $\mathrm{i}=A, B$, so that the number of generalists is $N_{G}=N-N_{A}-N_{B}$. Let $\tilde{N}_{A}$ be the total number of demanders with $A$ problems. $\tilde{N}_{A}$ is a binomial random variable with parameters $1 / 2$ and $N$. The number of demanders with $B$ problems is $\tilde{N}_{B}=N-\tilde{N}_{A}$. 
An equilibrium in this economy is characterized by a set of prices of solutions $\mathrm{p}_{\mathrm{A}}$ and $\mathrm{p}_{\mathrm{B}}$ for each demand realization; earnings of specialists and generalists, $\mathrm{w}_{\mathrm{G}}, \mathrm{w}_{\mathrm{A}}, \mathrm{w}_{\mathrm{B}}$; an allocation of agents to fields, $\mathrm{N}_{\mathrm{G}}, \mathrm{N}_{\mathrm{A}}, \mathrm{N}_{\mathrm{B}}$; and a vector of knowledge acquired by generalist and specialist managers and workers $\left(q_{m}^{i j}, q_{w}^{i j}\right)$ with $i=A, B$, and $j=$ specialist, generalist ${ }^{22}$ such that agents choose their field and knowledge optimally, organizational choices are optimal, and the market for solutions clears. In what follows, we obtain and characterize the equilibrium organization and level of specialization. We first obtain the equilibrium prices in each state of the world and the implications for the equilibrium utilization of workers' time and knowledge in any equilibrium; then we obtain the equilibrium prices and earnings conditional on specialization. Given these prices, we can obtain agents' knowledge (q) and managers' leverage (n) from constraint (2) and optimization (4). Finally we use these inputs to characterize the equilibrium level of specialization $\left(\mathrm{N}_{\mathrm{A}}, \mathrm{N}_{\mathrm{B}}, \mathrm{N}_{\mathrm{G}}\right)$ for a given size of the economy.

Field Specialization and Hierarchy. There are two relevant states of the world in each field. First, suppose that demand is sufficiently high to employ all the specialists in field A, $\tilde{N}_{A}>$ $N_{A}$. Since the value of production when problems are solved is 1 , and in this case suppliers can extract all of the surplus, the equilibrium price of solutions in field $A$ is $p_{A}=1$. On the other hand, if $\tilde{\mathrm{N}}_{\mathrm{A}}<\mathrm{N}_{\mathrm{A}}$ there are fewer $A$ problems than $A$-specialists: there is excess supply in field $A$. Equilibrium requires that $A$-specialists be indifferent between working and not working, so that the equilibrium price of a solved problem in field $\mathrm{A}$ is $p_{A}=0$. The expected price for field $A$ solutions then equals:

$$
p_{\mathrm{A}}^{\mathrm{e}}=\operatorname{Pr}\left[\tilde{\mathrm{N}}_{\mathrm{A}}>\mathrm{N}_{\mathrm{A}} \mid \mathrm{N}\right] .
$$

Given this expected price it is straightforward to obtain the expected earnings of specialists in each field. Substituting (5) in (4), the earnings of field i specialists equal:

$$
w_{i}\left(N_{i} \mid N\right)=\operatorname{Pr}\left[\tilde{\mathrm{N}}_{\mathrm{i}}>N_{i} \mid N\right] q_{m}^{i s^{*}}-c\left(q_{m}^{i s^{*}}\right)\left(1-q_{w}^{i s^{*}}\right)-c\left(q_{w}^{i s^{*}}\right) q_{w}^{i s^{*}}
$$

where the knowledge choices $q^{i s^{*}}$ are the result of optimization (4). Specialists' earnings are only a function of the size of the economy and the number of specialists in each field. Generalists,

\footnotetext{
${ }^{22}$ In what follows we suppress the field notation whenever it is clear from the context.
} 
who are arbitraging across fields, always receive a price of 1 for solutions in the field in which they work (see the proof of Proposition 2 below). By symmetry of the two sectors, they are equally likely to work in each field. The earnings of generalists are then given by:

$$
w_{G}=2\left(\frac{1}{2} q_{m}^{g^{*}}-c\left(q_{m}^{g^{*}}\right)\left(1-q_{w}^{g^{*}}\right)-c\left(q_{w}^{g^{*}}\right) q_{w}^{g^{*}}\right)
$$

Note that generalists' earnings are independent of both the realization of demand and of the number of specialists.

In the Appendix, we derive formally how organization and knowledge acquisition vary with field specialization. Informally, note first that, in equilibrium, a field $A$ specialist is more likely to work in field $A$ at a positive price than a generalist. When there is excess demand for field $A\left(\tilde{N}_{A}>N_{G}+N_{A}\right)$, all $A$-specialists and generalists work in $A$ for a positive price. When there is excess supply $\left(\tilde{N}_{A}<N_{A}\right)$, no agent receives a positive price in $A$. In between, all $A$-specialists, but only some generalists, work in $A$ for a positive price. The fact that $A$-specialists work more often in $A$ than generalists, in turn, implies that the returns to depth in field $A$ are greater for a field $A$ specialist than a generalist. As a result, field $A$ specialists learn more within field $A$ than generalists. Since managers who are specialists have more in depth knowledge to protect and leverage than those who are generalists, specialists are more likely to work in hierarchies than generalists and managers who are specialists are likely to be more leveraged.

Proposition 2. Specialists at a given hierarchical level acquire at least as much knowledge in their field as generalists at the same hierarchical level $\left(q_{m}, q_{w}\right)$; managers who are specialists are at least as leveraged (n) as generalists. Specialists are at least as likely as generalists to be in hierarchies $(n>0)$.

Equilibrium Field Specialization. An equilibrium number of specialists and generalists $\mathrm{N}_{\mathrm{i}}$ with both generalists and specialists requires the expected earnings of generalists and specialists to be equal, that is, from (6) and (7):

$$
w_{A}\left(N_{A} \mid N\right)=w_{B}\left(N_{B} \mid N\right)=w_{G} .
$$


It is easy to see that either a solution with both generalists and specialists does not exist or, if it does, is unique. ${ }^{23}$ For a given size of the economy $N$, increasing the number of specialists $N_{A}$ and $N_{B}$ monotonically decreases their expected earnings (6), as the likelihood that demand will be high enough to support positive prices decreases; on the other hand, it leaves unchanged generalists' earnings (7). Thus condition (8) uniquely determines the number of agents in each field.

\subsection{Hierarchies, Specialization, and the Extent of the Market}

Our main theoretical proposition concerns how individual specialization and hierarchical organization vary in equilibrium with the size of the economy, N. We use this proposition to motivate the empirical work below, which investigates how law offices' hierarchical organization varies across local markets.

Proposition 3. An increase in the size of the economy resulting in a proportionate increase in the supply of agents and demand for solutions jointly affects field specialization and hierarchies:

a. The number and proportion of field-specialized agents is non-decreasing in the size of the economy.

b. The proportion of agents in hierarchies (agents in teams with $n>0$ ) is non-decreasing in the size of the economy.

c. On average, managers' leverage is non-decreasing in the size of the economy.

Informally, as the size of the economy increases, the aggregate distribution of demands across fields becomes more certain. As a result, if the share of field i specialists stays constant, the probability that there is excess supply in field i decreases and specialists' earnings increase above those of generalists'. Returning to equilibrium requires increasing the share of field $\mathrm{i}$ specialists until their earnings are the same as generalists'. The point is clearest in the limit: with $\mathrm{N}$ very large, exactly $1 / 2$ of the problems are $A$ and $1 / 2$ are $B$ every time. Then the economy has $N / 2$ specialists of type $A$ and $N / 2$ specialists of type $\mathrm{B}$, and there is no need for generalists to arbitrage the differences in demand between the two fields. From Proposition 2, individuals'

\footnotetext{
${ }^{23}$ Setting up this equilibrium condition as an equality, given that $\mathrm{N}$ is discrete, requires that the population $\mathrm{N}$ is large enough that we can treat $\mathrm{N}$ as a continuous number.
} 
returns to depth increase when they field-specialize, and this, in turn, increases the returns to leveraging this knowledge over a larger number of agents.

The following two corollaries emphasize the mechanism through which these changes take place and show what happens when the conditions necessary for the comparative statics to be strict are not present. First, a crucial condition for the changes in organization and knowledge acquisition discussed is that the marginal returns to depth are positive. This requires problems to be sufficiently heterogeneous in learning costs, so that the cost of learning an interval of solutions is sufficiently convex. Absent that, increasing market size has no impact on hierarchies.

Corollary 4. When $C(q)$ is insufficiently convex, so that managers are at a corner with $q_{m}=1$, increases in the size of the economy lead the proportion of specialists to increase, but will have no effect on the proportion of agents in hierarchies or managers' leverage.

A second key necessary condition is that there be no binding constraints on the division of labor between managers and workers. By equation (2), constraints on the division of labor also constrain managers' leverage.

Corollary 5. When the proportion of problems that lower level workers may undertake is exogenously constrained, $q_{w} \leq q^{*}$, and this constraint is binding, changes in the size of the economy have no effect on the proportion of agents in hierarchies or managers' leverage.

To sum up, we propose that hierarchies increase the utilization of expert knowledge by allowing experts to specialize in problems they have a comparative advantage in addressing. That is, hierarchies enable experts to vertically specialize. It follows that if individuals become narrower as the size of the economy increases, their returns to depth increase, and as a result, the benefit of leveraging their expertise increases. As a consequence, hierarchies should be more prevalent and managerial leverage should be greater in larger economies. An additional implication of the model that Corollary 5 emphasizes is that constraints on the division of labor break the link between returns to specialization and hierarchy. This is because experts' leverage is limited by what lower-level individuals can do. Constraints on what lower-level individuals can do therefore limit the degree to which hierarchies can be used to help experts vertically 
specialize. Individuals at the top of hierarchies may become "narrower, but deeper" as the size of the economy increases, but this should not lead to organizational change. Below we will examine these central implications of the model empirically.

Our model does not allow for ex ante heterogeneity among individuals in, for example, cognitive ability. Extending it to incorporate such heterogeneity explicitly is beyond the scope of the paper. Garicano and Rossi-Hansberg (2003) develop a model that analyzes hierarchies in an environment where learning costs differ across individuals, and depict an equilibrium in which there is heterogeneity in organizational form and a correspondence between an individual's learning cost and their hierarchical position. ${ }^{24}$ Low- and high-learning-cost individuals work at the top and bottom of hierarchies, respectively, while medium-learning-cost individuals work in non-hierarchies. An implication of their model is that decreases in individuals' cost of deepening their knowledge lead the share of individuals who work in hierarchies to increase. The logic is very close to that in this paper: factors that lead experts to deepen their knowledge increase the returns to leveraging their expertise as a consequence. Thus, we expect that our model's central implications hold more generally in environments where individuals differ in their cognitive ability.

\section{Data}

\subsection{Data description}

The data are similar to those used in Garicano and Hubbard (2003). These data are establishment-level data on law offices collected by the Bureau of the Census as part of the 1992 Census of Services. As of 1992, law offices were generally relatively small enterprises: our data indicate that the median lawyer in this sector worked in an eight-lawyer office and the vast majority of lawyers worked in offices with fewer than twenty lawyers. Individuals who work at law offices supply the vast majority of legal services in the United States. ${ }^{25}$

Along with standard questions about revenues, payroll, and employment, the Census asks law offices questions about the organization of the office. The Census asks respondents how

\footnotetext{
${ }^{24}$ The Garicano-Rossi-Hansberg model considers an environment in which there is only one field. Thus, unlike the model in this paper, it does not analyze horizontal specialization or the impact of market size.

${ }^{25}$ The Bureau of Labor Statistics' Industry-Occupation Employment Matrix reports that in 2000, about 7\% of lawyers work as "in-house counsel," compared to about $80 \%$ who work out of law offices. Most of the rest work in a governmental agency or as judges.
} 
many lawyers work at the office, and among them, how many are partners versus associates. ${ }^{26}$ Another question asks respondents to report the number of lawyers who work primarily in each of thirteen specialized fields, and how many do not specialize in a single field ("general practitioners"). Thus, our data include office-level information on the hierarchical organization and field-specialization of lawyers. Finally, the Census asks offices the source of their revenues: the share that comes from individual clients, business clients, and other clients (such as governments). We use data from 1992 because it is the most recent year in which the Census asks the specialization question. Although we utilize the specialization data in part of our analysis, our main focus in this paper is on questions that ask about law offices' hierarchical structure: how many lawyers are partners versus associates. ${ }^{27}$

The Census also asks respondents to report the number of various categories of nonlawyers work at the office: "paraprofessionals," "managers and other nonlegal professional staff," and a catch-all category that includes all other workers. The distinction between lawyers and non-lawyers is sharp, and derived in part from legal restrictions on what non-lawyers can do for clients. Lawyers are individuals who are licensed to practice law. States require individuals to pass a bar examination in order to practice law, and most require them to have a degree from an accredited law school to take a bar examination. Although it is common for non-lawyers such as paralegals, legal secretaries, and the like to interact with clients in some fashion, there are limits on what they can do directly for clients regardless of their expertise. ${ }^{28}$ Non-lawyers are prohibited from representing clients in court or doing things that proxy for a court appearance such as conducting a deposition. Non-lawyers are also prohibited from offering clients legal advice directly, although they can communicate lawyers' advice to clients. These prohibitions limit the degree to which lawyers can delegate tasks to non-lawyers. While lawyers can ask paralegals or legal secretaries to serve as liaisons between them and clients, they are prohibited from delegating tasks to non-lawyers that would require non-lawyers to exercise professional judgment.

Like in our earlier work, we merge these data to other, county-level data sources. The

\footnotetext{
${ }^{26}$ There are distinctions within these categories in some firms (e.g., equity partners and non-equity partners). We do not dwell on these other distinctions because our data do not make them.

${ }^{27}$ Previous work (Garicano and Hubbard (2003)) utilized the specialization data to investigate the determinants of law firms' field boundaries.

${ }^{28}$ These prohibitions are derived from state laws governing unauthorized practice of the law. (Cannon, 1992)
} 
1992 County Business Patterns (CBP) provides us county-level data on employment, the distribution of employment across industries, and the employment size distribution of establishments. We compute employment shares for seven major one-digit industries (e.g., retail). We also compute an estimate of employees per establishment by one-digit industry, by multiplying employment size category shares reported in the CBP by the midpoints of the employment size categories. The 1994 City and County Data Book (CCDB) provides countylevel demographic data. We merged in a wide variety of demographic variables from this source. In the specifications below, we employ a vector of these that includes the fraction of population that is black, the fraction of population that is over seventy-five, the fraction of households that are families, the fraction of the population with a high school degree, income per capita, the percentage change in housing units between 1980 and 1990, and the government and federal government shares of employment. ${ }^{29}$

We use these variables as proxies for the size and distribution of demand for legal services coming from firms and individuals located in the county. The industry shares of employment and establishment size variables capture the extent to which demands for legal services come from different business sources. The CCDB data mainly captures differences in the distribution of demands from individuals: for example, one would expect the demand for probate work to be particularly high in counties where there is a large share of elderly people. ${ }^{30}$ If these variables capture cross-sectional differences in the distribution of local demands well, then one can think of increases in total employment, conditional on these variables, as rotations in the local demand curve for legal services: proportionate increases in the various legal issues encountered by businesses and individuals located in the county. We emphasize here that these rotations are defined in terms of the location of demands. They do not correspond to the aggregate demand curve faced by lawyers located in the county in circumstances where lawyers serve out-of-county demands. We discuss this issue in more depth below.

These data enable us to analyze the central implications of the above model, which are depicted in Proposition 3. We examine whether the share of lawyers that work in hierarchies is greater in larger local markets, and whether such increases are interrelated with increases in the

\footnotetext{
${ }^{29}$ We found little evidence that other CCDB variables are correlated with the distribution of local demands for legal services.

${ }^{30}$ We also construct a state capital dummy that equals one if the state capital is located in the county and zero otherwise, to capture distributional differences associated with government demands.
} 
share of lawyers who field-specialize. We also examine the degree to which increases in the share of lawyers working in hierarchies reflect increases in the share who are associates in hierarchies and partners in hierarchies. This provides further evidence regarding whether expertise is more leveraged in larger markets. In addition, we examine relationships between the share of individuals working at law offices who are lawyers and local market size. Contrasting results that depict the lawyer/non-lawyer margin with those at the partner/associate margin is of interest because the division of labor is more constrained at the former than the latter. Corollary 5 implies that one should expect relationships between market size and organizational form to be weaker for the former than the latter. We conduct our analysis across the legal services industry in general, and also within the business and individual segments. Finally, we examine whether the patterns we uncover appear when conditioning on the number of lawyers in the office: whether the organization of n-lawyer offices in small local markets differs from that of n-lawyer offices in large markets. This provides evidence whether our results just reflect "firm size effects" rather than the forces our model illuminates. We discuss our specifications in more detail in the results section. Combined, our evidence will shed light on hierarchies' role with respect to the production of legal services, specifically, whether it extends to the issues depicted in our model.

\subsection{Empirical Issues}

Hierarchies and Law Offices. The theory in Section 3 is a theory of hierarchical organization. In principle, hierarchies need not correspond to law offices' boundaries; they could include lawyers who work at different offices or firms. This raises an empirical issue because our data report which lawyers work in the same office; we do not directly observe which lawyers work with each other. We are therefore unable to detect all instances of hierarchies in the industry, such as when partners at one office play an associate-like role for partners at other offices. This limitation of our data forces us to make an assumption about the hierarchies' boundaries: that they are limited by offices' boundaries. We do not believe this assumption to be strong. While there are certainly exceptions, lawyers who work together on a client's problem (e.g., partners 
and associates) are usually based in the same office. ${ }^{31}$

Market Size and the Distribution of Demand. Our empirical exercise relates hierarchy to county-level employment, where the latter reflects the size of demand for legal services from local businesses and individuals. If counties are closed economies in the sense that clients are always served by lawyers located in the same county, our analytic framework would apply directly to the empirical exercise and market definition issues would not arise. Counties are not closed economies in this sense, however. Although many clients' demands are served by local lawyers, some are not. Top lawyers, particularly those in the business segment, tend to be located in large cities but serve a substantial number of non-local clients. These lawyers serve regional or national markets.

Our analytic framework, echoing work in the urban economics literature, helps explain why this is the case. In our model, scale economies associated with knowledge utilization imply that lawyers in small markets do not deepen their knowledge as much as lawyers in large markets. As a consequence, some of the problems clients in small markets encounter cannot be solved locally. They instead are solved by lawyers located in larger markets. Lawyers in such markets can better exploit increasing returns from knowledge because there are more local demanders, and this is compounded if they serve demands that originate in smaller markets as well. If the demands such lawyers serve are systematically different than those other lawyers serve - for example, if they tend to involve complicated legal issues encountered by businesses this would lead to an analytic problem: there might be unobserved differences in the demands that large- and small-market lawyers address. Finding that lawyers are organized differently in larger markets may reflect differences in the distribution of demands they serve rather what the theory above emphasizes: differences in lawyers' human capital.

We will examine whether our results reflect unobserved differences in the distribution of demand by comparing the results we obtain using our full sample to those we obtain when we use only offices located in counties that are relatively small and geographically isolated: counties that are either part of single-county Metropolitan Statistical Areas (MSAs) as defined by the U.S. Census Bureau or that are not part of MSAs. Restricting the analysis to single-county MSAs and

\footnotetext{
${ }^{31}$ Garicano and Santos (2004) provide one explanation why it is optimal for lawyers who refer work to one another, like in our model, to work in the same firm: partnership arrangements weaken individuals' incentives to withhold knowledge from each other.
} 
non-MSAs eliminates all counties with strong economic ties to other, neighboring counties and practically all large cities. The "small market subsample" that results excludes all suburban counties and includes none of the 50 largest MSAs in the United States. ${ }^{32}$ A full list of the single-county MSAs in this subsample is in Garicano and Hubbard (2003).

In Garicano and Hubbard (2003), we test the assumption that, conditional on our countylevel controls, the composition of demands is independent of county employment for our full and small market subsamples. We regressed the share of law offices' revenues that come from individuals on $\ln$ (county employment) and our controls. If lawyers in large markets serve out-ofmarket demands more than those in smaller markets, and if these out-of-market demands are disproportionately from businesses, then the share of law offices' revenues that come from individuals should decrease with county employment. In contrast, finding that the share of law offices' revenues that come from individuals does not vary with county employment would provide no evidence that the distribution of demands differs systematically with market size, conditional on our controls. We find that when we use our full sample, the share of law offices' revenues that come from individuals decreases with market size, especially when looking across relatively large counties: those with at least 200,000 employees. However, when we use our "small market subsample," we find no significant relationship between this revenue share and county employment, once we include the vector of controls we describe above. We reproduce these results in the Appendix for reference. ${ }^{33}$

This provides evidence that, within this subsample, the distribution of demands does not systematically differ with market size. We exploit this below by showing that our main empirical patterns are very similar when using the full and small market subsamples. This will provide evidence that our results are not driven by unobserved differences in the distribution of demand: they show up even in a part of the sample where we find no evidence that such differences are related to market size.

\footnotetext{
${ }^{32}$ There are four large single-county MSAs (Honolulu, Las Vegas, Phoenix, and San Diego) that are much larger than the rest. We exclude these from our small market subsample. The largest counties in this subsample have about 200,000 employees; these are where Albuquerque, NM; El Paso, TX; Fresno, CA, Lancaster, PA; Madison, $\mathrm{WI}$; and Tucson, AZ are located. Our results are robust to dropping these counties.

${ }^{33}$ Summarizing this result using cities in Texas, the demand faced by Houston-based lawyers is not simply a multiple of those faced by Lubbock-based lawyers; but to a first approximation, the demand faced by Lubbockbased lawyers is a multiple of those faced by Abilene-based lawyers.
} 
Census' Questions and Firms' Legal Form of Organization. A quirk in the survey reduces the number of offices that report the number of lawyers who are partners and associates separately. Law firms can be legally organized as sole proprietorships, partnerships, or professional service organizations ("PSOs") such as professional corporations. Although senior lawyers in a PSO are not considered "partners" for tax purposes - they are technically employees because their firm is organized as a corporation - there is little or no organizational difference between these lawyers and partners in law firms that are legally organized as partnerships. Lawyers and law firms distinguish between partners and associates in a way that is common across these legal forms of organization. However, the Census asks offices to only report lawyers as "partners" (or "proprietors") if they are defined as such for tax purposes. If a law firm is organized as a PSO, the data contain no information on the number of lawyers who are partners versus associates - all lawyers are reported to be associate lawyers. Thus, our analysis of hierarchies uses only firms that are legally organized as proprietorships or partnerships; these firms make up about two-thirds of the industry in terms of lawyers, offices, and revenues.

This raises the prospect of sample selection if law firms' decision to incorporate is not random. We have investigated this, and discuss the issue at length in the Appendix. Briefly, we found that law firms are far more likely to incorporate as PSOs in some states than others. We suspect that this reflects differences in when states allowed law firms to do so and differences in how state courts have interpreted the relevant legislation. Law firms' propensity to incorporate also differs, though less dramatically, with the number of lawyers: offices with 8-20 lawyers are more likely to be organized as PSOs than larger or smaller offices. In the Appendix we describe how we adjust the sampling weights assigned to each office in our data to account for this, increasing those for state-office size combinations where the share of offices organized as PSOs is high and decreasing those for combinations where the share is low. Our results are very similar when we use these adjusted weights rather than unadjusted weights, suggesting that sample selection in this dimension would not affect our conclusions even if we did nothing to account for it. In short, we do not think this is much of an issue.

\section{Empirical Results}


The next part of our empirical analysis examines relationships between organizational form and local market size: are lawyers in larger counties more likely to work in hierarchies? Table 2 contains results from three regressions that use our entire sample of law offices. These are linear probability models. The unit of observation in our data is the law office. The dependent variable equals one if the office is organized as a hierarchy (i.e., has at least one associate) and zero otherwise. The independent variables come from CBP and the CCDB as described above. These include the share of county employment in seven one-digit sectors, the average employment size of establishments in each of these sectors, a state capital dummy, and the demographic controls described above. We include this vector to control for cross-county differences in the distribution of demands from businesses located in the county. The variables of interest are the coefficients on our local market size variables, which are based on total employment in the county. Observations of law offices are weighted by the number of lawyers, ${ }^{34}$ so the coefficients on these variables can be interpreted as probability derivatives that relate the share of lawyers who work in hierarchies to a measure of local market size. All standard errors are robust (White (1980)). ${ }^{35}$

The first column reports results from a simple regression that contains only employment size variables and no controls. The coefficients are all positive and significant, and are larger for larger market sizes. A larger share of lawyers work in hierarchies in larger local markets. The coefficient on the $>1 \mathrm{M}$ dummy indicates a 52 percentage point difference in this share between very small and very large markets. The coefficients on the other dummies indicate that the relationship between the share of lawyers working in hierarchies and local market size exists across a broad range of market sizes; it does not just appear when comparing very small and very large local markets. The second column includes our full set of controls. The coefficients decrease, indicating that some of the relationship depicted in the first column reflects relationships between hierarchies and the composition of local demand, but the same general pattern appears. ${ }^{36}$ The last set of columns replace the market size dummies with $\ln$ (county employment). The R-squareds change little when doing so; including county employment as a

\footnotetext{
34 They are also weighted using Census sampling weights and the state-establishment size weights discussed above.

${ }^{35}$ We have also estimated "clustered" standard errors where the clustering is within-county; the standard errors differ little from those reported here.

${ }^{36}$ The decline in the coefficients when including the controls suggests that including additional controls would cause the coefficients to decline further. Below we will show within-segment results that diminish this concern.
} 
continuous variable rather than as a series of dummies does not sacrifice fit. The point estimate is positive and significantly different from zero. Its magnitude indicates that doubling market size is associated with a 4.3 percentage point increase in the share of lawyers who work in hierarchies. $^{37}$ Moving from a very small market to a large one is associated with about a 30 percentage point increase in this share. Thus, consistent with the theory outlined above, hierarchies are used more to organize lawyers in larger local markets.

\subsection{Field-Specialization, Hierarchy, and Local Market Size}

We next examine how these patterns relate to increases in the share of lawyers that fieldspecialize. Our model implies that increases in field-specialization and the share of individuals in hierarchies should be interrelated. To investigate this, we divide lawyers into four categories according to whether they field-specialize and whether they work in a hierarchy: "generalist, non-hierarchy," "specialist, non-hierarchy," "generalist, hierarchy," and "specialist, hierarchy." We examine how the shares of lawyers in these categories change with local market size. The specifications are analogous to those in the previous subsection, but the dependent variables are now shares rather than dummy variables: for example, the share of lawyers in the office that are in the "generalist, non-hierarchy" category. Finding that the "generalist, non-hierarchy" share decreases at the expense of the "specialist, hierarchy" share provides evidence consistent with the proposition that lawyers' hierarchical organization varies with their human capital.

Panel A of Table 3 contains the coefficient on $\ln$ (county employment) from four regressions. The dependent variable in the first column is share(generalist, non-hierarchy): the share of lawyers in the office who are generalists and do not work at an office with associates. ${ }^{38}$ The coefficient on $\ln$ (county employment) in this regression is negative and significant. The "generalist, non-hierarchy" share declines with local market size. The magnitude indicates that doubling local market size is associated with a 5 percentage point decrease in the share of lawyers who are generalists and work in non-hierarchies.

\footnotetext{
${ }^{37}$ Multiplying the parameter estimates by $\ln 2$ provides a point estimate of how much the share increases with a doubling of market size.

${ }^{38}$ The "hierarchy" part of this variable is determined at the office level; the "specialist" part varies across individuals in the office. All specifications reported in Table 3 contain the full set of controls described earlier.
} 
The other columns use the shares in the other three categories as the dependent variables. ${ }^{39}$ The coefficient on $\ln$ (county employment) in the specification where the dependent variable is share(specialist, hierarchy) is positive, significantly different from zero, and economically large. The main pattern in this panel is that the "specialist, hierarchy" share increases at the expense of the "generalist, non-hierarchy" share. We find no evidence that the "specialist, non-hierarchy" or the "generalist, hierarchy" shares increase with local market size; the negative and significant coefficient on $\ln$ (county employment) in the third column indicates that the "generalist, hierarchy" share actually decreases with local market size.

The point estimates imply large changes in the human capital and organization of lawyers across different-sized markets. They indicate that the share of lawyers in the "specialist, hierarchy" category increases by about 40 percentage points when moving from very small to very large local markets, while the share of lawyers in the "generalist, non-hierarchy" category drops by about 35 percentage points and the other two shares stay roughly constant. As market size increases, there is an increase in the share of lawyers that both field-specialize and work in hierarchies and a corresponding decrease in the share that do neither. These patterns fit well with our model, which implies that individuals should move from "generalist, non-hierarchy" to "specialist, hierarchy" as the returns to field-specialization increase.

\subsection{Partners and Associates}

We next explore the degree to which the increase in the share of lawyers in hierarchies splits between increases in the share of lawyers who are partners and associates. We do this with analogous regressions to above, where the dependent variables are the share of lawyers who are partners in hierarchies and the share who are associates, respectively.

Panel B of Table 3 contains the coefficient on $\ln$ (county employment) in two regressions, each of which contain the full vector of controls described above. The coefficient in the first column is from the specification that uses the share of lawyers who are partners in hierarchies as the dependent variable. The coefficient is not statistically significantly different from zero. There is no evidence that the share of individuals who are partners in hierarchies increases with

\footnotetext{
${ }^{39}$ The coefficients sum to zero by construction; the fourth is thus implied by the first three. Also, we note that we estimated each of these regressions separately. There is no gain in efficiency from estimating them jointly, given that the vector of explanatory variables in the individual equations are the same.
} 
local market size. The coefficient in the second column is from a specification that uses the share of lawyers who are associates as the dependent variable. The coefficient is positive and significant. The coefficient is 0.051 , indicating that doubling local market size is associated with a 3.5 percentage point increase in the share of lawyers who are associates.

Thus nearly all of the increase in the share of lawyers in hierarchies is accounted for by increases in the share of lawyers who are associates. As local market size increases, roughly the same fraction of lawyers are partners in hierarchies, but an increasing share are associates. In other words, the fraction of lawyers who are leveraged stays constant, but the average leverage among leveraged lawyers increases. This result is consistent with a central implication of the theory above, that on average, managerial leverage should be greater in larger local markets.

\subsection{Market Segments}

Table 4 reports results from specifications that use only the business segment subsample. Panel $\mathrm{A}$ is analogous to Table 2. The first column reports the coefficients on the local market size dummies in a specification that does not include the rest of the controls. The coefficient estimates are positive and significant. The point estimates are not statistically different from each other starting at $100 \mathrm{~K}-200 \mathrm{~K}$ employment, indicating the raw relationship between the hierarchy share and local market size in this segment is strongest when looking across relatively small markets. ${ }^{40}$ The second column includes our full vector of controls. The point estimates are all positive and significant, and increase with local market size. The share of lawyers in this segment working in hierarchies increases with local market size throughout the range of our sample. Comparing these results with those in first column of the table, we find that the point estimates change only slightly when including the vector of controls. ${ }^{41}$ The third column reports the coefficient on $\ln ($ county employment). The estimate is positive and significantly different from zero. Its magnitude indicates that doubling local market size is associated with a 5.6 percentage point increase in the share of lawyers working in hierarchies; this is larger than the magnitude reported in Table 2 when the sample included all lawyers.

\footnotetext{
${ }^{40}$ For reference, 200,000 employment is roughly the size of the counties in which Fresno, CA and Des Moines, IA are located.

${ }^{41}$ This suggests that the relationships between organizational form and local market size reported in this table do not primarily reflect compositional differences in local demands. If they did, one would expect that the coefficients on county employment dummies would differ more when including and excluding our vector of controls.
} 
Panels B and C are analogous to Table 3. The coefficient on $\ln$ (county employment) in the first column of panel B is negative and significant. The "generalist, hierarchy" share declines with local market size within the business segment. The magnitude indicates that doubling local market size is associated with a 3.2 percentage point decrease in the share of lawyers who are generalists and work in non-hierarchies. As in Table 2, there is no evidence that share(specialist, non-hierarchy) or share(generalist, hierarchy) increase with market size: the negative and significant coefficients indicate that they actually decrease. The coefficient on share(specialist, hierarchy) is 0.115 and statistically significantly different from zero: doubling market size is associated with an 8 percentage point increase in the share of lawyers in this category. Turning now to Panel C, the coefficient on share(partner, hierarchy) is not statistically different from zero and that on share(associate, hierarchy) is positive and significant.

Broadly, the business segment results are similar to the "all offices" results, but stronger. The share of lawyers working in hierarchies increases with local market size, this increase is interrelated with increases in lawyers' field specialization, and mainly reflects increases in the share of lawyers who are associates. The latter implies increasing leverage among partners in hierarchies.

Table 5 reports results from specifications that only use offices in the individual segment. These results differ sharply from those in Table 4. The estimates in the right two columns of Panel A provide no evidence of a relationship between the share of lawyers in hierarchies and local market size. In Panel B, the coefficient on share(generalist, non-hierarchy) is negative and significant. But unlike in Table 4, the coefficient on share(specialist, non-hierarchy) is positive and significant and the other two coefficients are not statistically different from zero. Within the individual segment, lawyers in larger local markets field-specialize more, but we find no evidence that they are more likely to work in hierarchies once they do so.

Relationships between hierarchy, local market size, and field specialization thus are stronger when looking at the business than the individual segment; in the latter, we find no evidence of relationships between the share of lawyers working in a hierarchy and local market size. One explanation is that this difference is related to Corollary 4, which states that relationships between hierarchy and local market size should not appear if learning costs are not sufficiently heterogeneous across problems. It may be the case that the vast majority of individual clients' legal problems involve routine work from lawyers' perspective, so that even 
non-specialized lawyers in small markets essentially learn the entire range of problems they confront. If so, one would not expect hierarchies to become more prevalent as local market size increases, even if lawyers field-specialize more, because vertical specialization would not become more valuable.

\subsection{Small Markets}

As we explain in the previous section, evidence in our previous paper indicates that the distribution of demand varies with market size in ways for which we cannot completely control when we use our full sample. We are far more confident in our ability to control for market sizerelated differences in the distribution of demand when we use our "small market subsample," which uses offices located in single-county MSAs and non-MSAs. If the above results were to go away when using this subsample, this would indicate that they could be driven by unobserved differences in the distribution of demand rather than variation in lawyers' human capital. Finding that the small market subsample results are similar to those using the full sample is evidence that the full sample results are not driven by such differences.

Table 6 shows our results. This table shows that the patterns in the small market subsample are very similar to those we uncovered using the full sample. The first column shows the coefficient estimates for $\ln$ (county employment) using only the business client offices in the full sample; these were reported in Table 4 as well. The second column reports estimates from analogous specifications, using only the small market subsample. The coefficient on "share(hierarchy)" is positive and significant in the small market subsample, and almost exactly the same magnitude as in the full sample. Moving down the table, there is a significant increase in "share(specialist, hierarchy)" at the expense of the other categories in both columns. And as in the full sample, the coefficient on "share(associate, hierarchy)" is positive and significant but that on "share(partner, hierarchy)" is not statistically significantly different from zero. The third and fourth columns report analogous estimates for the individual client offices. Once again, the estimates from the small market subsample are very similar to those that use the full sample.

Our main results thus appear when using only offices in single-county MSAs and nonMSAs. We interpret this as evidence that they do not reflect unobserved differences in the distribution of demand. 


\subsection{Is This All Just a Size Effect?}

Law firms located in large local markets tend to be larger than those in smaller ones. The theory above provides one reason why this is the case: lawyers can better exploit increasing returns from knowledge in larger markets, and this, in turn, leads some of them to leverage their expertise with associates. One reason firms will tend to be larger in larger markets is because hierarchical teams include more lawyers. Note that this view, in which increasing returns operate at the level of individual lawyers, implies that variation in firm size is simply a reflection of changes in lawyers' hierarchical organization. Firm size has no effect itself: it is an outcome driven entirely by organizational trade-offs. ${ }^{42}$

This is not the only possible view, however, and other views can imply that the direction of causation is reversed: that variation in firm size affects lawyers' hierarchical organization. For example, suppose there exist firm-level scale economies associated, perhaps, with the value associated with the firm's name. If these scale economies can be better exploited in large than small local markets, this will tend to lead firms in large markets to be larger than those in small markets. Suppose also that organizing individuals hierarchically is more valuable, the more individuals there are, perhaps because this reduces communication costs or improves incentives. Then one might observe that the share of lawyers working in hierarchies increases with local market size, but for reasons having nothing to do with the forces depicted in our model. The empirical phenomenon would instead reflect a "firm size effect."

We investigate this empirically by examining whether our results with respect to the business segment hold when conditioning on the number of lawyers in the office. We find evidence that they do, implying that the results above do not only reflect a size effect. ${ }^{43}$

Table 7 reports our results. The top panel reports results from specifications similar to the last column in Panel A of Table 4, but that use only offices with between two and seven lawyers. Single lawyer offices are never hierarchies, and offices with more than seven lawyers almost always have at least one associate: we therefore focus on part of the sample where there is

\footnotetext{
42 This organization-theoretic view of the determinants of firm size is shared by the recent literature on firms' boundaries (e.g., Grossman and Hart (1986)). In this view, increasing returns do not inherently operate at the firm level; instead, firms are but one of a set of institutions that can be used to exploit increasing returns.

${ }^{43}$ We have also done an analogous analysis of the individual segment, and find that none of the results from our previous section change: we continue to find no evidence that lawyers' hierarchical organization varies with local market size.
} 
variation in our dependent variable, a dummy that equals one if there is at least one associate. The first column contains the coefficient on $\ln$ (county employment) from our base specification; we omit the estimates associated with our control vector. The second reports this coefficient from a specification that also includes a set of dummies that indicate how many lawyers there are in the office. The coefficient is positive and significant in both columns. Conditional on the number of lawyers in the office, lawyers are more likely to work in a hierarchy in larger than smaller local markets.

The middle panel reports results from specifications analogous Panel B of Table 4, once again using the 2-7 lawyer office subsample. Like in Table 4, share(generalist, non-hierarchy) declines with market size but share(generalist, hierarchy) and share(specialist, non-hierarchy) do not increase; as before, they decrease. The coefficient on share(specialist, hierarchy) is positive and significant. To summarize, these results are very similar to those in Table 4. Controlling for the number of lawyers in the offices, lawyers' hierarchical organization varies with local market size, and this variation is interrelated with increases in lawyers' field specialization.

The bottom panel reports results analogous to Panel $\mathrm{C}$ of Table 4, which examines how the shares of lawyers who are partners in hierarchies and associates in hierarchies vary with local market size. Here we show results for large law offices as well: unlike in the other two panels, there is variation in the dependent variable among these offices because the partner and associate shares vary. The first row contains the coefficient on $\ln$ (county employment) in specifications where share(partner in hierarchy) is the dependent variable. It is negative and significant for the 8-20 and 20-67 lawyer office subsamples. The second row contains analogous results for specifications where share(associate) is the dependent variable. The coefficient is positive and significant in all subsamples except that which includes the very largest offices. Combined, these depict that leverage increases with local market size within office size categories.

In sum, law offices' hierarchical organization varies with market size, even when conditioning on the number of lawyers in the office. N-lawyer offices in large markets are organized differently than n-lawyer offices in small markets. They are more likely to be hierarchies and there are more associates per partner within hierarchies, and this variation is interrelated with higher levels of field specialization. We therefore conclude that the results discussed above do not just reflect firm size effects. 


\subsection{Lawyers and Non-Lawyers}

We also investigate whether the relationships between hierarchy and market size that we find when looking at partners and associates also hold when considering lawyers and nonlawyers. That is, we find that partners in hierarchies have greater leverage in terms of associates as market size increases: do lawyers have leverage in terms of non-lawyers?

Table 8 reports results with respect to this question. The dependent variable in each of the specifications is the share of individuals working out of the law office who are lawyers. The coefficients on the county employment dummies do not indicate a broad, positive relationship between law offices' organization and local market size. The columns on the right summarize our evidence. When looking at all offices in our sample, the coefficient on $\ln$ (county employment) is small and not statistically significantly different from zero. The coefficient is positive and statistically significantly different from zero within the business client segment, but the magnitude is quite small. Moving from a very small to a very large local market in our sample is associated with only a 4 percentage point increase in the non-lawyer share: on average offices move from $58 \%$ non-lawyers to $62 \%$ non-lawyers. In contrast, the results in Table 3 imply that moving from a very small market to a very large one is associated with a 25 percentage point increase in the share of lawyers who are associates.

Thus, we find that the relationship between local market size and law offices hierarchical organization is much weaker at the lawyer/non-lawyer margin than at the partner/associate margin. We view this as important evidence with respect to understanding the role of hierarchies in this context. The division of labor between lawyers and non-lawyers is not nearly as flexible as that between partners and associates; limits on what non-lawyers can do mean that they generally cannot substitute for lawyers. As depicted in Corollary 5, these limits weaken the link between returns to specialization and hierarchy. As market size increases and lawyers fieldspecialize more, it is possible for lawyers to specialize in higher-level problems by allocating more difficult problems to lawyers working under them, but less possible for lawyers to do so by increasing the scope of what their non-legal support staff does. This lends support to the general hypothesis that one role hierarchies play is in helping experts vertically specialize.

\subsection{The Distribution of Leverage}


We turn last to the distribution of leverage across all lawyers, including as in Section 2 unleveraged lawyers. Results in the previous sections indicate that on average, partners in hierarchies are more leveraged in larger local markets; here we characterize the distribution of leverage and show how it varies with local market size.

Table 9 contains two panels. The top characterizes the leverage distribution across lawyers within the business segment, by market size category. The first column reports the share of lawyers who are unleveraged: the share who are either associates or partners at firms without associates. The other columns report the average leverage among lawyers in the nth decile of the leverage distribution. ${ }^{44}$ From the top panel, the distribution of leverage across lawyers in the business segment becomes more skewed as market size increases. Moving from small to large markets, leverage increases more at the top of the leverage distribution than further down. This pattern also holds for the individual segment, but is not as strong.

We extend this analysis by running quantile regressions that investigate whether these relationships appear when controlling for local differences in the distribution of demands. Table 10 contains results from these regressions; in each, we include the vector of controls discussed above. For the business segment, we run these for the 65th, 75th, 85th, and 95th percentiles; leverage is zero below these percentiles for all market sizes. Similarly, we run these for the 85 th and 95th percentiles for the individual segment.

The coefficients on $\ln$ (county employment) are positive and significant in each of these regressions for the business segment: leverage increases with local market size at each point in the distribution examined here. By and large, the point estimates are higher when looking at higher percentiles. As local market size increases, leverage is distributed more unevenly across lawyers in general, but also when considering just partners in hierarchies. There is one exception to this: the point estimate in the $95^{\text {th }}$ percentile regressions is slightly less than that in the $85^{\text {th }}$ percentile regressions. In contrast, when we examine lawyers in the individual segment, neither of the coefficients on $\ln$ (county employment) are statistically significantly different from zero.

Figure 1 summarizes our results with respect to leverage for the business segment. The vertical axis depicts leverage and the horizontal axis depicts a lawyer's position in the leverage distribution within a market size category. The arrows depict what happens as local market size increases. The division between the unleveraged and leveraged lawyers stays the same. The

\footnotetext{
${ }^{44}$ Census non-disclosure requirements prevent us from simply reporting quantiles of the leverage distribution.
} 
slope of the right part of the line, which depicts leveraged lawyers, increases, reflecting that the distribution of leverage across lawyers is more skewed in larger markets. This is accompanied by a rightward shift of the line dividing associates and unleveraged partners.

We find this depiction of our results interesting because it implies links between the organizational issues we study in this paper and two other issues mentioned in the introduction: the distribution of earnings and the size distribution of firms. Figure 1 shows that the distribution of leverage across lawyers is unequal, and inequality in leverage increases when moving from small to large local markets. These patterns may be reflected as well in the distribution of lawyers' earnings and size distribution of firms. A goal of future research is to investigate relationships between the leverage distribution and the earnings distribution and between the leverage distribution and the size distribution of firms in this industry.

\section{Conclusion}

This paper examines hierarchies' role in the organization of knowledge-intensive production. Our theory highlights a key function hierarchies can play in such contexts: they can help exploit increasing returns to acquired knowledge by allowing experts to specialize in problems they have a comparative advantage in addressing. It follows, as we show, that individuals' hierarchical organization should change with the extent of the market. When the extent of the market increases, individuals' knowledge becomes narrower, but deeper. Managerial leverage, the number of workers per manager, optimally increases to exploit this depth. Our theory shows how and why managerial leverage is, to paraphrase Smith, limited by the extent of the market.

We then provide systematic empirical evidence, using office-level data from the U.S. Census. We find that lawyers' hierarchical organization changes with the extent of the market. Changes in hierarchy take the shape of a move from low-leverage and unleveraged generalists to leveraged specialists, and appear primarily in sectors where vertical specialization is most valuable and at hierarchical margins where the division of labor is least constrained. These facts support the view that hierarchies help exploit increasing returns from knowledge in this context.

Other findings indicate patterns that alternative views of hierarchies, including those that emphasize the problem of monitoring or coordinating teams of associates, cannot accommodate, 
and provide evidence against alternative interpretations of our empirical results that revolve around unobserved differences in the distribution of demands or firm size effects.

Our theoretical and empirical findings indicate several interesting avenues for research. First, the fact that individuals leverage their expertise through hierarchies more when they are more specialized has important implications for cross-sectional differences in wage inequality. In particular, cross-sectional differences in the skewness of leverage suggest cross-sectional differences in wage inequality. Theoretical work has shown how hierarchies enhance abilityrelated wage inequality (Rosen (1982), Garicano and Rossi-Hansberg (2003)), but this has not yet been investigated empirically. Second, the relationship between individual specialization and leverage has implications for the size distribution of firms (Sutton (1991, 1998), Ijiri and Simon (1977)). Our previous work (Garicano and Hubbard (2003)) indicated that law firms' boundaries reflect organizational trade-offs, and that firms' field scope tends to narrow as market size increases and individuals field-specialize. The current findings illuminate how scale economies associated with human capital lead partners to become more leveraged, and thus the size of work groups to increase, as market size increases and individuals field-specialize. Inequality in wages and inequality in firm size are central issues in the labor and industrial organization literatures, respectively, but neither literature examines the organizational underpinnings of inequality. We plan to explore these issues further in future work. 


\section{References}

Alchian, Armen A. and Demsetz, Harold. "Production, Information Costs, and Economic Organization." American Economic Review, 62 (December 1972): 777-95.

Arrow, Kenneth. "The Economic Implications of Learning by Doing." Review of Economic Studies, 29 (June 1962): 155-173.

Athey, Susan; Milgrom, Paul; and Roberts, John. "Robust Comparative Statics." Stanford University, 1998.

Bolton, Patrick, and Dewatripont, Patrick. "The Firm As a Communication Network." Quarterly Journal of Economics 109 (November 1994): 809-39.

Bureau of the Census. 1992 Census of Service Industries: Miscellaneous Subjects, Washington, G.P.O., 1996.

Calvo, Guillermo A. and Wellisz, Stanislaw. "Supervision, Loss of Control, and the Optimum Size of the Firm." Journal of Political Economy 86 (October 1978): 943-952.

Calvo, Guillermo A. and Wellisz, Stanislaw. "Hierarchy, Ability, and Income Distribution." Journal of Political Economy 87 (October 1979): 991-1010.

Cannon, Therese A. Ethics and Professional Responsibility for Legal Assistants. Boston, Little, Brown, 1992.

Carmichael, H. Lorne. "Incentives in Academics: Why Is There Tenure?" Journal of Political Economy, 96 (June 1988): 453-472.

Crémer, Jacques. "A Partial Theory of the Optimal Organization of a Bureaucracy." Bell Journal of Economics 11 (Autumn 1980): 683-693.

Galanter, Marc and Palay, Thomas. Tournament of Lawyers: The Transformation of the Big Law Firm. University of Chicago Press, Chicago, 1991.

Garicano, Luis. "Hierarchies and the Organization of Knowledge in Production." Journal of Political Economy 108 (October 2000): 874-904. 
Garicano, Luis and Hubbard, Thomas N. "Specialization, Firms and Markets: The Division of Labor Within and Between Law Firms." University of Chicago, November 2003.

Garicano, Luis and Rossi-Hansberg, Esteban. "Organization and Inequality in a Knowledge Economy.” University of Chicago, July 2003.

Garicano, Luis and Santos, Jesus. "Referrals." American Economic Review, forthcoming, 2004.

Geanakoplos, John and Milgrom, Paul. "A Theory of Hierarchies Based on Limited Managerial Attention." Journal of the Japanese and International Economy 5 (September 1991): 205-25.

Grossman, Sanford J., and Hart, Oliver D. "The Costs and Benefits of Ownership: A Theory of Vertical and Lateral Integration." Journal of Political Economy 94 (August 1986): 691-719.

Hart, Oliver and John Moore. "On the Design of Hierarchies: Coordination vs. Specialization." London School of Economics, August 2003.

Heinz, John P., and Laumann, Edward O. Chicago Lawyers: The Social Structure of the Bar, Evanston, Northwestern University Press, 1982.

Ijiri, Yuji and Simon, Herbert. Skew Distributions and the Sizes of Business Firms. North-Holland, Amsterdam, 1977.

Johnson, Norman L.; Kotz, Samuel; and Kemp, Adrienne. Univariate Discrete Distributions. Wiley, New York, 1992.

Kordana, Kevin A. "Law Firms and Associate Careers: Tournament Theory Versus the Production-Imperative Model,” Yale Law Journal, 104 (May 1995): 1907-1934.

Lazear, Edward P. Personnel Economics. MIT Press, Cambridge, 1995. 
Lazear, Edward P., and Sherwin Rosen. "Rank-order Tournaments as Optimum Labor Contracts." Journal of Political Economy 89 (October 1981): 841-64.

Levin, Jonathan, and Steven Tadelis. "Profit Sharing and the Role of Professional Partnerships.” Stanford University, February 2004.

Marglin, Stephen A. "What Do Bosses Do? The Origins and Functions of Hierarchy in Capitalist Production.” The Review of Radical Political Economics 6 (Summer 1974): 60-112.

Mincer, Jacob. "Investment in Human Capital and Personal Income Distribution," Journal of Political Economy 66 (August 1958): 281-302.

Murphy, Kevin M. "Specialization and Human Capital.” Unpublished Ph.D. Dissertation, University of Chicago, 1986.

Radner, Roy. "Hierarchy: The Economics of Managing." Journal of Economic Literature 30 (September 1992): 1382-415.

Radner, Roy. "The Organization of Decentralized Information Processing." Econometrica 61, (September 1993): 1109-46.

Radner, Roy, and Timothy Van Zandt. "Information Processing in Firms and Returns to Scale." Annales D'Economie Et De Statistique 25-26 (1992): 265-98.

Rajan, Raghuram, and Julie Wulf. "The Flattening Firm: Evidence From Panel Data On the Changing Nature of Corporate Hierarchies," University of Chicago, 2003.

Rajan, Raghuram, and Luigi Zingales. "Power in a Theory of the Firm." Quarterly Journal of Economics 113 (May 1998), 387-432.

Rebitzer, James B. "Radical Political Economy and the Economics of Labor Markets." Journal of Economic Literature, 31 (September 1993): 1394-1434.

Romer, Paul. "Increasing Returns and Long-Run Growth." Journal of Political Economy, 94 (October 1986):1002-1037. 
Rosen, Sherwin. "Authority, Control and the Distribution of Earnings," Bell Journal of Economics, 13 (Fall 1982): 311-323.

—_."Specialization and Human Capital." Journal of Labor Economics, 1 (January 1983): 43-49.

—_. "Markets and Diversity." American Economic Review, 92 (March 2002): 1-15.

Qian, Yingyi. "Incentives and Loss of Control in an Optimal Hierarchy," Review of Economic Studies, 61 (July 1994): 527-44.

Sander, Richard H. and Williams, Douglass. "A Little Theorizing About the Big Law Firm: Galanter, Palay, and the Economics of Growth." Law and Social Inquiry, 18 (Summer 1992): 391.

Sutton, John. Sunk Costs and Market Structure: Price Competition, Advertising, and the Evolution of Concentration, Cambridge, MIT Press, 1991.

Sutton, John. Technology and Market Structure: Theory and History, Cambridge, MIT Press, 1998.

Van Zandt, Timothy. "Real-time Decentralized Information Processing as a Model of Organizations with Boundedly Rational Agents" Review of Economic Studies 66 (July 1999): 3358.

White, Halbert. "A Heteroskedasticity-Consistent Covariance Matrix Estimator and a Direct Test for Heteroskedasticity." Econometrica 48 (May 1980): 817-838. 


\section{Appendix}

\section{A.1. Proofs of Section 3 Propositions}

\section{Proposition 1.}

The optimization problem is:

$$
\max _{q_{m}, q_{w}} p^{e} q_{m}-c\left(q_{m}\right)\left(1-q_{w}\right)-c\left(q_{w}\right) q_{w}
$$

It is easy to see that the objective function is supermodular in both arguments $\left(\mathrm{q}_{\mathrm{m}}\right.$ and $\left.\mathrm{q}_{\mathrm{w}}\right)$ and the parameter $p^{\mathrm{e}}$. It follows that (see Athey, Milgrom and Roberts, 1998), $\mathrm{q}_{\mathrm{m}}$ and $\mathrm{q}_{\mathrm{w}}$ are nondecreasing in $\mathrm{p}^{\mathrm{e}}$.

\section{Proposition 2}

We show that (a) generalists are more likely than specialists to work at a positive price; then that (b) a specialist in field $\mathrm{i}$ is more likely to be employed at a positive price in field $\mathrm{i}$ than a generalist; (c) and that, as a result, a specialist acquires at least as much knowledge as a generalist at the same level, is at least as leveraged, and is at least as likely to be in a hierarchy.

a. If demand in both fields is greater than the number of specialists in each field, $\tilde{N}_{A}>N_{A}$ and $\tilde{N}_{B}>N_{B}$, both fields have positive prices (since both the supply of solvers and demand for solutions equal $\mathrm{N}$ ). If there is excess supply in one sector, $\tilde{N}_{A}<N_{A}$, then there is excess demand $\tilde{N}_{B}>N_{B}+N_{\mathrm{G}}$ and thus positive prices in the other sector, since $\tilde{N}_{A}+\tilde{N}_{B}=N_{A}+N_{B}+N_{G}$. In both cases, all generalists supply at positive prices, while, in the latter case, specialists in one of the fields face a market price of zero. Each of these cases happens with positive probability.

b. Consider field A. If $\tilde{N}_{A}<N_{A}$, then the market price in field A equals zero, and no agent employed in the field receives a positive price. If $\tilde{N}_{A}>N_{A}+\mathrm{N}_{\mathrm{G}}$ then prices in field A are positive and prices in field B are zero even if all generalists work in field A. Thus, all generalists work in field A and all agents employed in the field receive a positive price. In these two cases, generalists and A-specialists are equally likely to be employed at a positive price in field A. In between, if $N_{A}+\mathrm{N}_{\mathrm{G}}>\tilde{N}_{A}>N_{A}$, generalists allocate themselves across fields until prices are equal in each field and supply just equals demand. In this case, all field A specialists are employed at a 
positive price in field A, but only some generalists are employed at a positive price in field A. Thus, overall, A-specialists are more likely to be employed at a positive price in field A than generalists.

c. It follows from $\mathrm{a}$ and $\mathrm{b}$ and symmetry that the ex ante probability that a generalist works in a given field is $1 / 2$. Also, from $b$, the probability that earnings are positive in a particular field is larger than $1 / 2, \operatorname{Pr}\left[\tilde{N}_{i}>N_{i}\right]>1 / 2$. It follows from Proposition 1 that knowledge and spans are non-decreasing in $\mathrm{p}_{\mathrm{A}}{ }^{\mathrm{e}}$. This implies that specialists in each field acquire at least as much knowledge of that field as generalists at the same level in the hierarchy, and as a result, that managers who are specialists are at least as leveraged (n) as generalists. In particular, specialists are at least as likely as generalists to be in hierarchies.

\section{Proposition 3}

There are three possible cases, depending on whether an interior solution for the number of specialists in the economy exists:

$$
\begin{aligned}
& w_{A}(N / 2 \mid N)>w_{g} \\
& w_{A}\left(N_{A} \mid N\right)=w_{B}\left(N_{B} \mid N\right)=w_{g} \\
& w_{A}(1 \mid N)<w_{g}
\end{aligned}
$$

First, suppose specialists and generalists coexist so that the relevant equilibrium condition is (A.7). Then the earnings of generalists, given by the right hand side of equation (A.7), are unaffected by an increase in $\mathrm{N}$. The reason is that in a larger economy, there are more problems to be solved, but also more problem solvers - generalists are still fully employed regardless of economy size. Now consider the left hand side of equation (A.7). When $\mathrm{N}$ increases, the earnings of specialized agents always increase - it becomes less likely that there will be excess supply in their field. To see this note that:

$$
\operatorname{Pr}\left[\tilde{N}_{A}>N_{A} \mid N\right]=\sum_{i=N_{A}}^{N}\left(\begin{array}{c}
N \\
i
\end{array}\right) p^{i}(1-p)^{N-i}
$$

Equilibrium requires that, as $\mathrm{N}$ increases, $\mathrm{N}_{\mathrm{A}}$ increase so that $\operatorname{Pr}\left[\tilde{N}_{A}>N_{A} \mid N\right]$, and hence $\mathrm{w}_{\mathrm{A}}$, remains constant and equal to $\mathrm{w}_{\mathrm{g}}(\mathrm{A} .7)$. In fact, equilibrium requires an increase not only in the number, but also in the proportion of specialists, $\mathrm{N}_{\mathrm{A}} / \mathrm{N}$, as we show next.

Johnson, Kotz and Kemp, (1992., p. 114) describe the following approximation to $\operatorname{Pr}\left[\tilde{N}_{A}\right.$ $\left.>N_{A} \mid N\right]$ as the best as long as $\mathrm{N} \mathrm{p}(1-\mathrm{p})>9$ (or, since $\mathrm{p}=1 / 2$ in our case, $\mathrm{N}>36$ ): 


$$
\operatorname{Pr}\left[\tilde{N}_{A}>N_{A} \mid N\right] \doteq \Phi\left[\frac{N_{A}+\frac{1}{2}-N p}{\sqrt{N p(1-p)}}\right]
$$

This approximation is most precise at $\mathrm{p}=1 / 2$, where the approximation error is smaller than $(7$. $\left.10^{-4}(\mathrm{~Np}(1-\mathrm{p}))^{-1 / 2}\right)$. For $\operatorname{Pr}\left[\tilde{N}_{A}>N_{A} \mid N\right]$ to remain constant, as $\mathrm{N}$ increases it is necessary that the argument in $\Phi($.$) be constant, that is, letting \operatorname{Pr}\left[\tilde{N}_{A}>N_{A} \mid N\right]=k$ :

$$
N_{A}+\frac{1}{2}-\frac{N}{2} \doteq \frac{1}{2} \sqrt{N} k
$$

Proving the proposition requires proving that $\mathrm{N}_{\mathrm{A}} / \mathrm{N}$ is increasing in $\mathrm{N}$, or, equivalently, that $\mathrm{N}_{\mathrm{A}}$ is elastic in N. In fact, from (A.11) it is easy to see that this is indeed the case:

$$
\frac{d \ln N_{A}}{d \ln N} \doteq \frac{1}{2}\left(\frac{\sqrt{N}}{2 N_{A}} k+\frac{N}{N_{A}}\right)>1
$$

The (strict) inequality follows from the fact that $\mathrm{N}_{\mathrm{A}} / \mathrm{N}<1 / 2$ by symmetry of fields $\mathrm{A}$ and $\mathrm{B}$ and by the fact there are some generalists in equilibrium (recall we are in the region where condition (A.7) holds) and $\mathrm{k} \geq 0$ since it is a probability. This shows part (a) of the proposition when (A.7) applies. $^{45}$

To understand the intuition, note that, by the Central Limit Theorem, the variance of the field distribution of demand in the larger economy is smaller, and for a given proportion of specialists $\mathrm{N}_{\mathrm{A}} / \mathrm{N}$ in each of fields $A$ and $B$ (which are always, by symmetry, not larger than $1 / 2$ ) the probability mass $\operatorname{Pr}\left[\tilde{N}_{A}>N_{A} \mid N\right]$ increases. Returning to equilibrium requires increasing the proportion of specialists $\mathrm{N}_{\mathrm{A}} / \mathrm{N}$.

Second, suppose now that condition (A.6) holds, so that all agents are specialists, that is $N_{A}=1 / 2$ and $N_{B}=1 / 2$. Then an increase in the size of the market $N$ weakly increases their earnings by the arguments above, so that equilibrium condition (A.6) continues to hold.

Third, suppose (A.8) holds, so that all agents are generalists. Then, by the arguments above, an increase in $\mathrm{N}$ leads to an increase in the wage of specialists. This leads either to an equilibrium determined by (A.7), with $\mathrm{N}_{\mathrm{A}}>0$ and $\mathrm{N}_{\mathrm{B}}>0$, or, if the increase is not large enough, (A.8) continues to hold and all agents continue to be only generalists.

\footnotetext{
${ }^{45}$ The above argument, which relies on a continuous approximation, abstracts from the fact that $\mathrm{N}_{\mathrm{A}}$ and $\mathrm{N}$ are discrete. Thus the argument only holds exactly for sufficiently large economies.
} 
Taking all three cases together the proportion of specialists is non-decreasing in the size of the market, and strictly increasing when (A.7) holds.

b. and c. follow from a. and from Proposition 2.

\section{Corollary 4.}

When $\mathrm{C}(\mathrm{q})$ is not sufficiently convex, the optimum is found at the corner with $q_{m}=1$ and $\mathrm{q}_{\mathrm{w}}$ that maximizes (4) for $q_{m}=1$. In this optimization $p^{e}$ is just an additive constant and plays no role in the choice of optimum $q_{w}$. Thus market effects play no role in the choice of either knowledge or the size of the team, fixed at $n+1=1 /\left(1-q_{w}\right)$.

\section{Corollary 5.}

This corollary follows straightforwardly from Proposition 3 and the time constraint (2), linking the span of control of managers to the knowledge of subordinates. The time constraint requires that $\mathrm{n}+1=1 /\left(1-\mathrm{q}_{\mathrm{w}}\right)$; thus if $\mathrm{q}_{\mathrm{w}}$ is fixed, $\mathrm{n}$ is fixed. If increasing $\mathrm{q}_{\mathrm{w}}$ is is not possible, increases in the size of the economy $\mathrm{N}$ have no impact on hierarchy.

\section{A. 2. Discussion of Analysis of the Determinants of Firms' Legal Form of Organization}

The fact that the Census does not ask offices to distinguish between partners and associates when firms are incorporated as PSOs raises the prospect of sample selection if law firms' decision to incorporate is not random, as firms with characteristics that make them likely to incorporate would be underrepresented in our analysis. We have read industry accounts and analyzed both the publicly-available data and our microdata to investigate whether this is likely to be the case. Briefly, industry accounts indicate that some states began to allow professional service firms to incorporate starting in the early 1960s. Other states followed, and many law firms began to incorporate, especially starting in the mid-1970s when Federal tax treatment of professional corporations was resolved. Incorporation provided for (a) tax-advantaged treatment of fringe benefits and (b) limited liability for actions taken by other lawyers in the firm. ${ }^{46}$ It had few other effects; only lawyers practicing within the firm were allowed to be shareholders, and revenues were generally not retained by the corporation.

\footnotetext{
${ }^{46}$ Unlimited liability remained for lawyers' own actions or the actions of those working under them. The tax advantage of incorporation was sharply reduced in the early 1980s, when the tax treatment of fringe benefits at unincorporated firms became comparable to that at incorporated firms.
} 
We analyzed patterns in law firms' legal form of organization to examine which types of firms were most likely to organize as a PSO, and thus along which dimensions selection would be most likely a problem. Data published by the Bureau of the Census indicates some striking state effects: the share of lawyers in PSOs tends to be very similar across cities within the same state. State effects are striking when examining different cities in the same state: the share of lawyers in PSOs tends to be very similar. For example, data published by the Bureau of the Census indicates that the share of lawyers working in PSOs is between 64-70\% in each of the six largest MSAs in Florida (Miami, Tampa, Ft. Lauderdale, Orlando, West Palm Beach, and Jacksonville), but is between $17-25 \%$ in each of the six largest MSAs in New York (New York, Nassau-Suffolk, Buffalo, Rochester, Syracuse, and Dutchess County). ${ }^{47}$ While we have not yet found a conclusive explanation for these effects, we suspect that they reflect some combination of differences in when states allowed law firms to incorporate as PSOs and differences in how state courts have interpreted this legislation. Using our microdata, we found a significant relationship between the state in which an office is located and the probability that the office is part of a firm that is organized as a PSO, and the $\mathrm{R}^{2}$ in a simple linear regression of a "PSO dummy" on state dummies is 0.09 . We also found a persistent, but weaker, relationship between firm size and legal form of organization. Offices with 8-20 lawyers are more likely to be organized as PSOs than smaller or larger offices; including office size dummies in the linear regression described above leads the $\mathrm{R}^{2}$ to increase to $0.14{ }^{48}$ We have also included variables that depict the share of lawyers in each specialized field in this regression. Some of these coefficients on these variables are statistically significant, but they do not improve the explanatory power of the regression much: the $\mathrm{R}^{2}$ increases only to 0.16 . State and (to a lesser extent) office size are correlated with firms' legal form of organization; conditional on these, firms' offerings play less of a role.

We use this analysis as a basis to adjust our sample to account for selection related to firms' legal form of organization. We divide our overall sample into cells defined by state-office size interactions and calculate the share of establishments within each cell that are organized as

\footnotetext{
${ }^{47}$ Bureau of the Census (1996). Florida and New York are near the extremes in terms of the share of lawyers in PSOs, but the similarity of PSO shares across different-sized MSAs in the same state extends to other states. For example, the PSO shares in the eight largest California MSAs are all between 34-40\% except San Francisco, which is $27 \%$.

${ }^{48}$ We defined six establishment size categories by number of lawyers: 1, 2-3, 4-7, 8-20, 21-67, and 68 or more. These categories contain approximately equal shares of lawyers in our sample.
} 
PSOs. We then use these shares as weights for the "partnership or proprietorship subsample." For example, if $30 \%$ of establishments in a cell are organized as PSOs, observations in this subsample are given a weight of (1/(1-0.3)). Effectively, this adjustment gives additional weight to observations in states such as Florida where the PSO share is high relative to observations in states such as New York where it is low. Comparing results when applying these weights to those when not doing so, we find little evidence of differences, suggesting that sample selection would not affect our conclusions much even if we did not attempt to account for it. 


\section{Table 1}

\section{Basic Facts About Legal Services Hierarchies}

United States, 1992

Panel A: Distribution of Law Offices and Associates by Number of Associates in the Office (percent)

\begin{tabular}{|c|c|c|c|c|c|c|c|}
\hline & & & & umbe & & & \\
\hline & 0 & 1 & 2 & 3 & 4 & 5 & $>5$ \\
\hline Distribution of Law Offices & 72.7 & 11.2 & 5.4 & 2.8 & 1.4 & 1.6 & 4.9 \\
\hline Distribution of Associates & & 8.4 & 8.0 & 6.4 & 4.2 & 6.1 & 66.9 \\
\hline
\end{tabular}

Panel B: Distribution of Law Offices and Share of Lawyers Who Are Specialists, by Associate/Partner Ratio (percent)

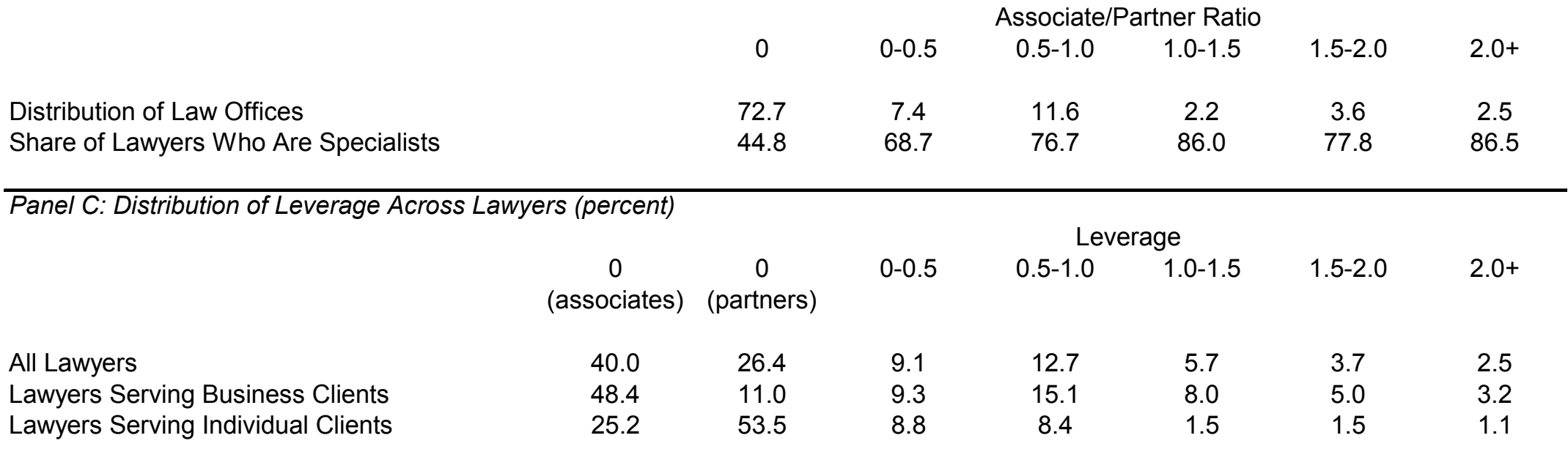

Leverage equals zero for all associates and for partners in offices without associates, and equals the associate/partner ratio in the office for partners in offices with associates. 


\section{Table 2}

\section{County Size and the Share of Lawyers Working in Hierarchies}

County Employment Dummies:

$\begin{array}{lll}20-100 \mathrm{~K} & \mathbf{0 . 2 1 7} & \mathbf{0 . 1 5 0} \\ & \mathbf{( 0 . 0 3 2 )} & \mathbf{( 0 . 0 4 2 )} \\ & & \\ 100-200 \mathrm{~K} & \mathbf{0 . 3 0 3} & \mathbf{0 . 1 6 9} \\ & (\mathbf{0 . 0 3 7 )} & \mathbf{( 0 . 0 5 5 )} \\ & & \\ 200-400 \mathrm{~K} & \mathbf{0 . 4 0 6} & \mathbf{0 . 2 1 0} \\ & (\mathbf{0 . 0 3 7 )} & \mathbf{( 0 . 0 6 1 )} \\ & & \\ 400 \mathrm{~K}-1 \mathrm{M} & \mathbf{0 . 4 6 3} & \mathbf{0 . 2 3 6} \\ & \mathbf{( 0 . 0 3 9 )} & \mathbf{( 0 . 0 6 3 )} \\ & & \\ >1 \mathrm{M} & \mathbf{0 . 5 2 0} & \mathbf{0 . 2 8 6} \\ & (\mathbf{0 . 0 2 7}) & \mathbf{( 0 . 0 7 9 )}\end{array}$

In(employment)

0.062

$(0.014)$

Controls?

$\mathrm{N}$

Y

Y

R-Squared

0.15

0.15

The dependent variable in each regression is a dummy that equals one if the office has a positive number of associates and zero if it has none. Observations are weighted by the product of the Census sampling weight and the number of lawyers in the office.

Controls include sectoral employment shares, average employment size of establishment by sector, state capital, demographic controls. $\mathrm{N}=11633$

Bold indicates statistically significantly different from zero using a two-sided t-test of size 0.05 . 


\section{Table 3}

\section{Field Specialization and Hierarchy}

Panel A: County Size, Field Specialization, and Hierarchy

Dependent Variable:

Share

Share

Share

Share

(generalist, non-hierarchy) (specialist, non-hierarchy)

(generalist, hierarchy)

(specialist, hierarchy)

In(employment)

$-0.070$

0.009

$(0.011)$

$-0.023$

0.085

$(0.010)$

(0.011)

(0.014)

Panel B: County Size, Partners, and Associates

Dependent Variable:

Share(partner, hierarchy) Share(associate, hierarchy)

In(employment)

0.010

0.051

(0.008)

(0.008)

Observations are weighted by the product of the Census sampling weight and the number of lawyers in the office.

Controls include sectoral employment shares, average employment size of establishment by sector, state capital, demographic controls

$\mathrm{N}=11633$

Bold indicates statistically significantly different from zero using a two-sided t-test of size 0.05 . 
Table 4

Business Segment Results

Panel A: County Size and the Share of Lawyers Working in Hierarchies

Dependent Variable:

Share

(hierarchy)

County Employment Dummies:

\begin{tabular}{|c|c|c|}
\hline $20-100 \mathrm{~K}$ & $\begin{array}{c}0.287 \\
(0.050)\end{array}$ & $\begin{array}{c}0.259 \\
(0.057)\end{array}$ \\
\hline $100-200 K$ & $\begin{array}{c}0.403 \\
(0.050)\end{array}$ & $\begin{array}{c}0.369 \\
(0.065)\end{array}$ \\
\hline $200-400 \mathrm{~K}$ & $\begin{array}{l}0.426 \\
(0.052)\end{array}$ & $\begin{array}{c}0.370 \\
(0.065)\end{array}$ \\
\hline $400 \mathrm{~K}-1 \mathrm{M}$ & $\begin{array}{l}0.487 \\
(0.048)\end{array}$ & $\begin{array}{c}0.419 \\
(0.071)\end{array}$ \\
\hline$>1 \mathrm{M}$ & $\begin{array}{c}0.499 \\
(0.049)\end{array}$ & $\begin{array}{c}0.447 \\
(0.075)\end{array}$ \\
\hline
\end{tabular}

$\ln ($ employment)

$0.075)$

Controls?

$\mathrm{N}$

0.081

$(0.011)$

$\mathrm{Y}-\mathrm{Y}$

Panel B: County Size, Field Specialization, and Hierarchy

$\begin{array}{lcccc}\text { Dependent Variable: } & \begin{array}{c}\text { Share } \\ \text { (generalist, } \\ \text { non-hierarchy) }\end{array} & \begin{array}{c}\text { Share } \\ \text { (specialist, } \\ \text { non-hierarchy) }\end{array} & \begin{array}{c}\text { Share } \\ \text { (generalist, } \\ \text { hierarchy) }\end{array} & \begin{array}{c}\text { Share } \\ \text { (specialist, } \\ \text { hierarchy) }\end{array} \\ \text { In(employment) } & \begin{array}{c}-0.046 \\ (0.007)\end{array} & -0.035 & -0.033 & 0.115 \\ & & (0.009) & (0.016) & (0.018)\end{array}$

Panel C: County Size, Partners, and Associates

$\begin{array}{lcc}\text { Dependent Variable: } & \begin{array}{c}\text { Share } \\ \text { (partner, } \\ \text { hierarchy) }\end{array} & \begin{array}{c}\text { Share } \\ \text { (associate, } \\ \text { hierarchy) }\end{array} \\ \text { In(employment) } & 0.012 & \mathbf{0 . 0 7 0} \\ & (0.008) & \mathbf{( 0 . 0 0 7 )}\end{array}$

Observations are weighted by the product of the Census sampling weight and the number of lawyers in the office.

Controls include sectoral employment shares, average employment size of establishment by sector, state capital, demographic controls. $\mathrm{N}=6262$.

Bold indicates statistically significantly different from zero using a two-sided t-test of size 0.05 . 
Table 5

Individual Segment Results

\section{Panel A: County Size and the Share of Lawyers Working in Hierarchies}

Dependent Variable:

Share

(hierarchy)

County Employment Dummies:

$\begin{array}{lll}20-100 \mathrm{~K} & \mathbf{0 . 1 1 9} & 0.080 \\ & \mathbf{( 0 . 0 4 3 )} & (0.053) \\ & & \\ \text { 100-200K } & \mathbf{0 . 1 0 4} & 0.011 \\ & \mathbf{( 0 . 0 5 2 )} & (0.072) \\ & & \\ 200-400 \mathrm{~K} & \mathbf{0 . 1 9 2} & 0.025 \\ & \mathbf{( 0 . 0 5 7 )} & (0.080) \\ & & \\ 400 \mathrm{~K}-1 \mathrm{M} & \mathbf{0 . 1 1 3} & -0.053 \\ & \mathbf{( 0 . 0 6 4 )} & (0.088) \\ >1 \mathrm{M} & & \\ & \mathbf{0 . 2 2 8} & 0.047 \\ & \mathbf{( 0 . 1 0 2 )} & (0.136)\end{array}$

In(employment)

0.010

(0.023)

Controls?

$\mathrm{N}$

Y

Y

Panel B: County Size, Field Specialization, and Hierarchy

Dependent Variable:

$\begin{array}{cccc}\text { Share } & \text { Share } & \text { Share } & \text { Share } \\ \text { (generalist } & \text { (specialist, } & \text { (generalist } & \text { (specialist }\end{array}$ non-hierarchy) non-hierarchy) hierarchy) hierarchy)

In(employment)

$\begin{array}{cccc}\mathbf{- 0 . 0 8 4} & \mathbf{0 . 0 7 4} & -0.023 & 0.033 \\ \mathbf{( 0 . 0 1 7 )} & \mathbf{( 0 . 0 2 0 )} & (0.013) & (0.019)\end{array}$

Panel C: County Size, Partners, and Associates

Dependent Variable:

Share Share

(partner, (associate,

hierarchy) hierarchy)

In(employment)

$\begin{array}{ll}-0.007 & 0.017\end{array}$

$(0.012) \quad(0.012)$

Observations are weighted by the product of the Census sampling weight and the number of lawyers in the office.

Controls include sectoral employment shares, average employment size of establishment by sector, state capital, demographic controls. $\mathrm{N}=5371$.

Bold indicates statistically significantly different from zero using a two-sided t-test of size 0.05 . 


\section{Table 6}

\section{County Size and the Share of Lawyers Working in Hierarchies}

Comparing Results From the Full and Small Market Subsamples

\begin{tabular}{cccc} 
Business & Client Offices & \multicolumn{2}{c}{ Individual Client Offices } \\
& & & \\
Full & Small Market & Full & Small Market \\
Sample & Subsample & Sample & Subsample
\end{tabular}

Dependent Variable:

\begin{tabular}{lcccc} 
Share(hierarchy) & $\mathbf{0 . 0 8 1}$ & $\mathbf{0 . 0 8 5}$ & 0.010 & -0.024 \\
& $\mathbf{( 0 . 0 1 1 )}$ & $\mathbf{( 0 . 0 3 3 )}$ & $(0.023)$ & $(0.033)$ \\
\hline Share(generalist, non-hierarchy) & $\mathbf{0 . 0 4 6}$ & $\mathbf{- 0 . 0 8 0}$ & $\mathbf{- 0 . 0 8 4}$ & $\mathbf{- 0 . 0 6 4}$ \\
& $\mathbf{( 0 . 0 0 7 )}$ & $\mathbf{( 0 . 0 2 7 )}$ & $\mathbf{( 0 . 0 1 7 )}$ & $\mathbf{( 0 . 0 2 9 )}$ \\
& & & & \\
Share(specialist, non-hierarchy) & $\mathbf{- 0 . 0 3 5}$ & -0.004 & $\mathbf{0 . 0 7 4}$ & $\mathbf{0 . 0 8 8}$ \\
& $\mathbf{( 0 . 0 0 9 )}$ & $(0.019)$ & $\mathbf{( 0 . 0 2 0 )}$ & $\mathbf{( 0 . 0 2 2 )}$ \\
Share(generalist, hierarchy) & $\mathbf{- 0 . 0 3 3}$ & $\mathbf{- 0 . 0 8 2}$ & -0.023 & 0.002 \\
& $\mathbf{( 0 . 0 1 6 )}$ & $\mathbf{( 0 . 0 3 1 )}$ & $(0.013)$ & $(0.019)$ \\
Share(specialist, hierarchy) & $\mathbf{0 . 1 1 5}$ & $\mathbf{0 . 1 6 7}$ & 0.033 & -0.026 \\
& $\mathbf{( 0 . 0 1 8 )}$ & $\mathbf{( 0 . 0 3 0 )}$ & $(0.019)$ & $(0.037)$ \\
& & & & \\
\hline Share(partner, hierarchy) & 0.012 & 0.030 & -0.007 & -0.022 \\
& $(0.008)$ & $(0.022)$ & $(0.012)$ & $(0.024)$ \\
Share(associate, hierarchy) & $\mathbf{0 . 0 7 0}$ & $\mathbf{0 . 0 5 5}$ & 0.017 & -0.002 \\
& $\mathbf{( 0 . 0 0 7 )}$ & $\mathbf{( 0 . 0 1 8 )}$ & $(0.012)$ & $(0.013)$ \\
& & & & 2355
\end{tabular}

Controls include sectoral employment shares, average employment size of establishment by sector, state capital, demographic controls. Bold indicates statistically significantly different from zero using a two-sided t-test of size 0.05 .

Small Market Subsample includes offices located in single-county MSAs and non-MSAs. 


\section{Table 7}

County Size and the Share of Lawyers Working in Hierarchies

Within Office Size Categories, Business Segment Only
2-7
$2-7$
Number of Lawyers
$8-20$
21-67
68 or more

Dependent Variable:

Share(hierarchy)

$0.109 \quad 0.071$

(0.032) (0.024)

\begin{tabular}{|c|c|c|c|c|c|}
\hline Share(generalist, non-hierarchy) & $\begin{array}{l}-0.070 \\
(0.019)\end{array}$ & $\begin{array}{l}-0.052 \\
(0.017)\end{array}$ & & & \\
\hline Share(specialist, non-hierarchy) & $\begin{array}{l}-0.039 \\
(0.021)\end{array}$ & $\begin{array}{l}-0.019 \\
(0.019)\end{array}$ & & & \\
\hline Share(generalist, hierarchy) & $\begin{array}{l}-0.099 \\
(0.043)\end{array}$ & $\begin{array}{l}-0.078 \\
(0.028)\end{array}$ & & & \\
\hline Share(specialist, hierarchy) & $\begin{array}{l}0.208 \\
(0.037)\end{array}$ & $\begin{array}{l}0.150 \\
(0.030)\end{array}$ & & & \\
\hline Share(partner, hierarchy) & $\begin{array}{c}0.021 \\
(0.018)\end{array}$ & $\begin{array}{l}0.003 \\
(0.014)\end{array}$ & $\begin{array}{l}-0.053 \\
(0.013)\end{array}$ & $\begin{array}{l}-0.040 \\
(0.010)\end{array}$ & $\begin{array}{c}0.001 \\
(0.014)\end{array}$ \\
\hline Share(associate, hierarchy) & $\begin{array}{l}0.088 \\
(0.019)\end{array}$ & $\begin{array}{l}0.068 \\
(0.015)\end{array}$ & $\begin{array}{c}0.069 \\
(0.012)\end{array}$ & $\begin{array}{l}0.042 \\
(0.010)\end{array}$ & $\begin{array}{l}-0.001 \\
(0.014)\end{array}$ \\
\hline $\begin{array}{l}\text { Controls include } \\
\text { number of lawyers dummies? }\end{array}$ & $\mathrm{N}$ & $\mathrm{Y}$ & $\mathrm{N}$ & $\mathrm{N}$ & $\mathrm{N}$ \\
\hline$N$ & 2081 & 2081 & 1371 & 828 & 314 \\
\hline
\end{tabular}

Controls include sectoral employment shares, average employment size of establishment by sector, state capital, demographic controls. Bold indicates statistically significantly different from zero using a two-sided t-test of size 0.05 . 


\section{Table 8}

\section{County Size and the Share of Non-Lawyers Working in Law Offices}

\begin{tabular}{|c|c|c|c|c|c|c|}
\hline $\begin{array}{l}\text { All } \\
\text { ffices }\end{array}$ & $\begin{array}{r}\text { Busines } \\
\text { Clients }\end{array}$ & $\begin{array}{c}\text { Individual } \\
\text { Clients }\end{array}$ & $\begin{array}{l}\text { Business } \\
\text { Clients }\end{array}$ & $\begin{array}{l}\text { Individual } \\
\text { Clients }\end{array}$ & $\begin{array}{c}\text { All } \\
\text { Offices }\end{array}$ & $\begin{array}{l}\text { Business } \\
\text { Clients }\end{array}$ \\
\hline
\end{tabular}

County Employment Dummies:

\begin{tabular}{|c|c|c|c|c|c|c|}
\hline $20-100 K$ & $\begin{array}{c}0.072 \\
(0.033)\end{array}$ & $\begin{array}{c}0.101 \\
(0.012)\end{array}$ & $\begin{array}{c}0.108 \\
(0.046)\end{array}$ & $\begin{array}{c}0.049 \\
(0.028)\end{array}$ & $\begin{array}{c}0.029 \\
(0.016)\end{array}$ & $\begin{array}{c}0.058 \\
(0.023)\end{array}$ \\
\hline $100-200 K$ & $\begin{array}{c}0.035 \\
(0.009)\end{array}$ & $\begin{array}{c}0.033 \\
(0.013)\end{array}$ & $\begin{array}{c}0.038 \\
(0.014)\end{array}$ & $\begin{array}{c}0.009 \\
(0.030)\end{array}$ & $\begin{array}{c}0.063 \\
(0.019)\end{array}$ & $\begin{array}{l}-0.006 \\
(0.032)\end{array}$ \\
\hline $200-400 \mathrm{~K}$ & $\begin{array}{c}-0.008 \\
(0.009)\end{array}$ & $\begin{array}{l}-0.005 \\
(0.014)\end{array}$ & $\begin{array}{l}-0.011 \\
(0.014)\end{array}$ & $\begin{array}{l}-0.024 \\
(0.029)\end{array}$ & $\begin{array}{c}0.035 \\
(0.018)\end{array}$ & $\begin{array}{l}-0.056 \\
(0.035)\end{array}$ \\
\hline $400 \mathrm{~K}-1 \mathrm{M}$ & $\begin{array}{c}0.040 \\
(0.039)\end{array}$ & $\begin{array}{c}0.005 \\
(0.013)\end{array}$ & $\begin{array}{c}0.121 \\
(0.095)\end{array}$ & $\begin{array}{c}0.018 \\
(0.024)\end{array}$ & $\begin{array}{c}0.049 \\
(0.022)\end{array}$ & $\begin{array}{c}0.019 \\
(0.036)\end{array}$ \\
\hline$>1 \mathrm{M}$ & $\begin{array}{c}0.023 \\
(0.009)\end{array}$ & $\begin{array}{c}0.019 \\
(0.012)\end{array}$ & $\begin{array}{c}0.047 \\
(0.028)\end{array}$ & $\begin{array}{c}-0.016 \\
(0.037)\end{array}$ & $\begin{array}{c}0.041 \\
(0.023)\end{array}$ & $\begin{array}{c}0.006 \\
(0.053)\end{array}$ \\
\hline
\end{tabular}

In(employment)

$\begin{array}{lll}-0.010 & \mathbf{0 . 0 0 8} & -0.014\end{array}$

$\begin{array}{lll}(0.010) & \mathbf{( 0 . 0 0 4 )} \quad(0.011)\end{array}$

Controls?

R-Squared
N N

0.11

$0.10 \quad 0.02$

\section{Y}

0.15

\section{Y}

0.13

\section{Y}

0.07
Y

0.15

\section{Y}

Y

$0.13 \quad 0.06$

The dependent variable in each regression is the share of individuals working in the office that are non-lawyers.

Observations are weighted by the product of the Census sampling weight and the number of (lawyers + nonlawyers) in the office.

Controls include sectoral employment shares, average employment size of establishment by sector, state capital, demographic controls. $\mathrm{N}=11633,5371$, and 6262, respectively for the all offices, individual clients, and business clients samples.

Bold indicates statistically significantly different from zero using a two-sided t-test of size 0.05 . 
Table 9

The Distribution of Leverage Across Lawyers

Averages, by Leverage Decile
Local
Share
6th
7th $\begin{gathered}\text { Leverage Decile } \\ 8 \text { th }\end{gathered}$
9th $\quad 10$ th

Offices in Business Segment Only

$\begin{array}{lcccccc}0-20 \mathrm{~K} & 73.1 & 0 & 0 & \text { (D) } & 0.48 & 1.13 \\ 20-100 \mathrm{~K} & 57.9 & \text { (D) } & 0.25 & 0.45 & 0.70 & 1.49 \\ 100-200 \mathrm{~K} & 56.3 & \text { (D) } & 0.42 & 0.64 & 0.93 & 1.83 \\ 200-400 \mathrm{~K} & 56.2 & \text { (D) } & 0.46 & 0.68 & 0.95 & 1.92 \\ 400 \mathrm{~K}-1 \mathrm{M} & 57.9 & \text { (D) } & 0.62 & 0.95 & 1.29 & 2.06 \\ >1 \mathrm{M} & 63.8 & 0 & \text { (D) } & 0.92 & 1.45 & 2.68 \\ & & & & & & \\ \text { All } & 59.4 & \text { (D) } & 0.40 & 0.76 & 1.13 & 2.13\end{array}$

Offices in Individual Segment Only

\begin{tabular}{|c|c|c|c|c|c|c|}
\hline $0-20 K$ & 81.3 & 0 & 0 & 0 & (D) & 1.08 \\
\hline 20-100K & 76.8 & 0 & 0 & (D) & 0.48 & 1.38 \\
\hline $100-200 K$ & 78.1 & 0 & 0 & (D) & 0.51 & 1.31 \\
\hline $200-400 K$ & 77.3 & 0 & 0 & (D) & 0.83 & 2.39 \\
\hline $400 \mathrm{~K}-1 \mathrm{M}$ & 82.2 & 0 & 0 & 0 & (D) & 1.78 \\
\hline$>1 \mathrm{M}$ & 76.2 & 0 & 0 & (D) & 0.84 & 1.96 \\
\hline All & 78.7 & 0 & 0 & (D) & 0.47 & \\
\hline
\end{tabular}

Leverage equals zero for associates and for partners at firms without associates, and equals the offices associate/partner ratio for partners at firms with associates.

Figure in cells with (D) are withheld for disclosure reasons. 
Table 10

County Size and the Distribution of Leverage

Quantile Regressions

Quantile:

65th

75th

85th

95th

Offices in Business Segment Only

In(employment)

$0.055 \quad 0.120$

0.184

0.140

$(0.017)$

(0.031)

(0.023)

(0.023)

Offices in Individual Segment Only

$\ln ($ employment)

$0.021 \quad 0.040$

$(0.024) \quad(0.026)$

Observations are weighted by the product of the Census sampling weight and the number of lawyers.

Dependent variable in both regressions is leverage. Leverage equals zero for associates

and for partners at firms without associates, and equals the offices associate/partner ratio for partners at firms with associates.

$\mathrm{N}=10121$ and 9115 , respectively for the business and individual client subsamples.

Bold indicates statistically significantly different from zero using a two-sided t-test of size 0.05 . 


\section{Figure 1}

The Distribution of Leverage

Business Segment Lawyers

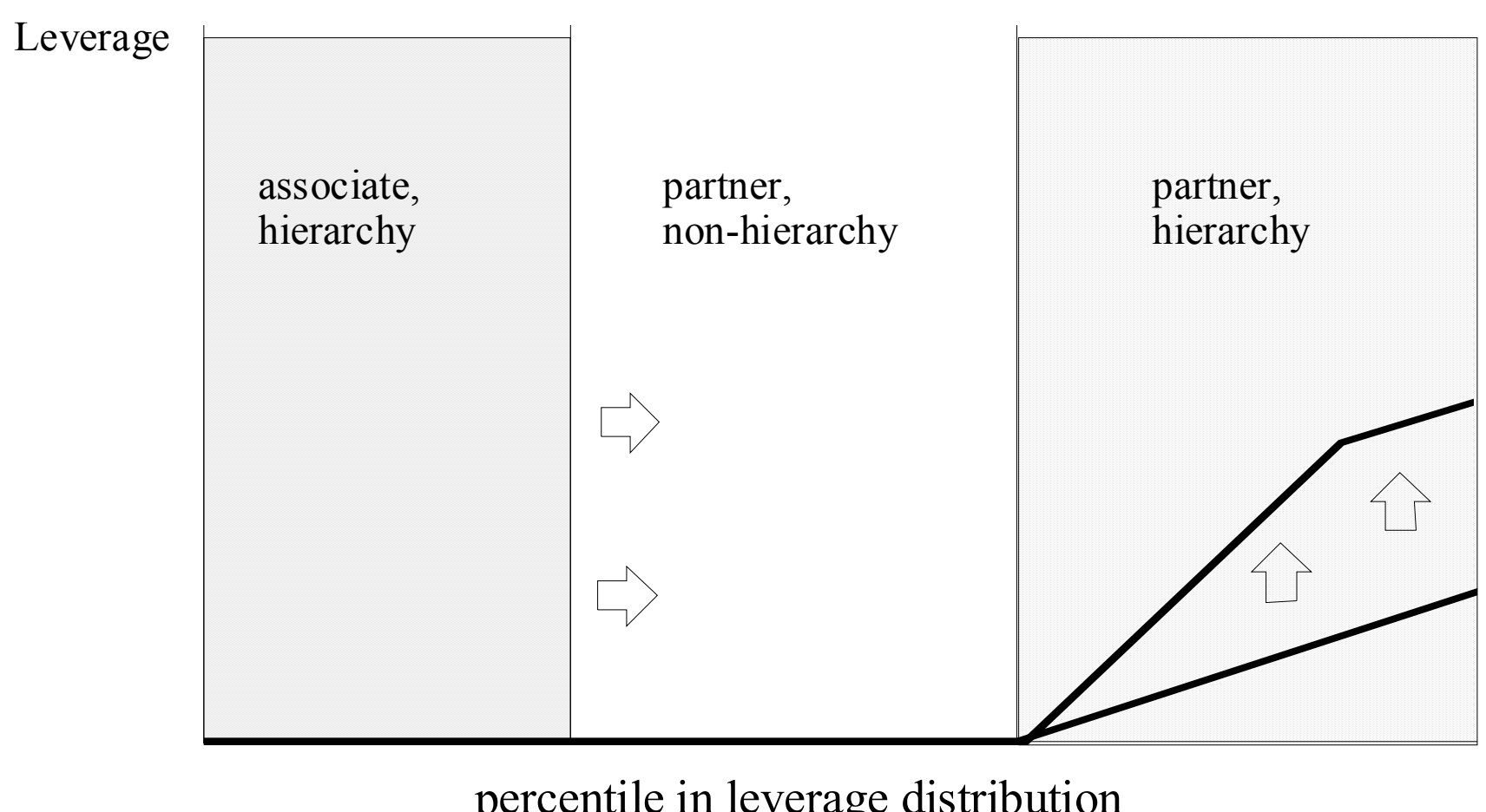

Arrows indicate how the distribution changes as local market size increases. 


\section{Table A1}

\section{Share of Revenues from Individual Clients and Market Size}

Dependent Variable: Percentage of Law Office's Revenues That Come From Clients Who Are Individuals.

Employment 20K-100K

Employment 100K-200K

Employment 200K-400K

mployment $400 \mathrm{~K}-1 \mathrm{M}$

Employment $>1 \mathrm{M}$

In(employment)

C

Includes Controls?

$\mathrm{N}$

Small market subsample includes law offices in non-MSAs and in single-county MSAs with less than 225,000 employment. Standard errors are clustered at the county level, and are reported in parentheses.

Bold indicates statistically significantly different from zero, using a two-sided t-test of size 0.05

The number of observations differs from that in other results because of missing values for the dependent variable.
Small Market Subsample

Full Sample

$\begin{array}{cc}\mathbf{- 8 . 7 5} & 1.04 \\ \mathbf{( 1 . 4 7 )} & (2.03) \\ & \\ \mathbf{- 2 0 . 2 7} & -4.00 \\ \mathbf{( 2 . 4 9 )} & (2.90) \\ & \\ \mathbf{- 2 7 . 5 0} & -5.97 \\ \mathbf{( 2 . 2 3 )} & (3.37)\end{array}$

$-36.19 \quad-11.85$

(3.09) (4.11)

$-43.74 \quad-19.11$

(2.76) (4.31)

$-1.57$

(1.07)

$-4.42$

(0.82)

N

Y

Y

N

Y

Y 